\title{
Evaluation and Analysis Model of the Length of Added Displaced Left-Turn Lane Based on Entropy Evaluation Method
}

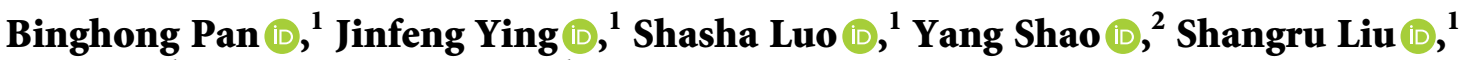 \\ Xiang Li, ${ }^{1}$ and Zhenjiang Xie $\mathbb{D}^{1}$ \\ ${ }^{1}$ Highway School, Chang'an University of Shaanxi Province, Xi'an 710064, China \\ ${ }^{2}$ School of Modern Posts (Logistics School) and Institute of Posts, Xi'an University of Posts and Telecommunications, \\ Xi'an 710121, China \\ Correspondence should be addressed to Binghong Pan; panbh@chd.edu.cn
}

Received 12 June 2021; Revised 25 August 2021; Accepted 24 September 2021; Published 12 October 2021

Academic Editor: Erfan Hassannayebi

Copyright $(92021$ Binghong Pan et al. This is an open access article distributed under the Creative Commons Attribution License, which permits unrestricted use, distribution, and reproduction in any medium, provided the original work is properly cited.

As the number of vehicles continues to grow in China, the problem of urban traffic congestion gets more serious, particularly at intersections. As a new type of unconventional intersection, the displaced left-turn (DLT) intersection has been widely recognized to improve the efficiency of intersections with heavy left-turn traffic flows. Converting an existing intersection into an intersection with additional DLT lanes is a valuable solution. However, the studies on DLT intersections mainly focus on performance, applicability, and safety. The guidelines on the specific engineering design process mostly come from experience, and the study on the considering multifactor design method is still insufficient. Therefore, this paper proposed an evaluation and analysis model of the lengths of added DLT lanes based on the entropy evaluation method, in which VISSIM and Surrogate Safety Assessment Model (SSAM) software were adopted for simulation. A design process for the length of the added DLT lanes was proposed with this model. An urban intersection in Xi' an was taken as a case study, and the application of the model and the design process was studied in detail. After selecting four evaluation indicators, the model was applied to calculate and analyze the optimal length of the added DLT lanes under 45 different traffic volume combinations. The recommended lengths of different situations were within the range recommended in the guidebook published by Federal Highway Administration. The results of the case study proved that the model proposed in this paper was advanced, reasonable, and practical.

\section{Introduction}

Since the beginning of the 21st century, the process of urbanization has accelerated and the size of cities has grown in China. Subsequently, the number of vehicles continues to rise, and the urban road traffic congestion problem is getting ever more serious. By the end of 2020, the "2020 China Urban Traffic Report" showed that the traffic congestion problem was still severe, among which the average speed of vehicles was basically around $30 \mathrm{~km} / \mathrm{h}$ during the peak commuting hours [1]. This undoubtedly presented that the traffic efficiency of urban roads in peak hours still needed to be improved immediately, and the reduction of traffic efficiency also has a certain impact on the economic and social development of the whole city. Therefore, it is still a significant need for the study to alleviate the problem of urban traffic congestion.

As an important joint of a road network, intersections are essential for improving the traffic efficiency of the entire road network. Some researchers have pointed out that the operational efficiency of an entire urban road network is often affected by some bottleneck sections. Moreover, urban intersections are often the bottleneck sections of urban roads [2]. To alleviate the congestion problem of urban road intersections, many scholars have studied how to improve the efficiency of intersections with different aspects, such as the new geometric form of intersections, signal timing optimization, and new traffic management technologies. Some scholars have studied the performance of the new U-turn intersections [3, 4], fan-shaped intersections [5], double- 
torsional intersections [6], and parallel flow intersections [7]. The different characteristics of various new alternative intersections have also been summarized [8]. For signal timing control, some scholars have proposed some simple intersection signal control strategies based on different methods $[9,10]$. Then, with the development of Internet of Vehicles and autonomous driving technology, some scholars have proposed signal models with the trajectory data of autonomous driving and Internet of Vehicles to optimize signal control [11]. In addition, as the "people-oriented" concept has gradually become a consensus, the signal control method of optimization has been proposed to comprehensively consider the total delay of pedestrians and vehicles passing an intersection [12]. There have also been attempts to improve the traffic conditions at intersections with the new traffic management. For traffic management, some scholars have used Internet of Things technology to propose a real-time optimization control model of the intersection traffic flow [13, 14], while some researchers have also studied how to use the Internet of Things technology to enhance the efficiency of intersections [15].

In addition to the above methods of the overall improvement of the intersection, left-turning traffic flows are essential to improving the crossing capacity and safety in the range of intersections because left-turning traffic flows are most likely to cause conflicts when running in intersections. Some scholars have conducted a detailed investigation and analysis on the operation of left-turning vehicles at intersections [16]. There were also a lot of results of solving the problem of left-turning traffic flows at intersections. To be more specific, some scholars have studied the improvement effect of VISSIM-based simulation and evaluated the operational impact of left-turn waiting areas at signalized intersections $[17,18]$. Some studies have proposed to set up reasonable modeling for left-lane line extensions [19]. A method for the dynamic use of the left-turn lane for opposite through traffic to improve the efficiency of a signalized intersection has also been proposed [20]. Some scholars have studied the effect of U-turn facilities [21], while other scholars have specialized in optimizing the phase of left-turn signals at intersections to improve left-turning traffic problems [22].

The displaced left-turn (DLT) intersection is the new type of unconventional intersection and focuses on improving the operation of left-turning traffic flows. The DLT intersection is also referred to as the continuous flow intersection (CFI) in many studies. The core design concept of a DLT intersection is to set up a subintersection before leftturning vehicles enter the main intersection so that leftturning vehicles can change to the outside of the opposite lanes in advance and eliminate the conflicts between leftturning traffic flows and the opposite straight traffic flow at the main intersection [23]. Due to the elimination of conflicts between left-turning traffic flows and opposite straight traffic flows, straight and left-turning vehicles at the main intersection can be green at the same time. To date, some scholars have carried out meaningful studies on DLT intersections, such as the applicability of displaced left-turn intersections, and have put forward two forms: partial and complete DLT intersections [7]. Through observation data of actual DLT intersections, the advantages of DLT intersections with improving traffic safety in turning can be found [24]. In addition, other scholars have also studied the safety of DLT intersections by using before-and-after comparison group and cross-sectional analysis methods and then pointed out that DLT intersections need to be equipped with traffic signs and traffic-calming facilities to achieve better use results [25]. Some scholars have put forward signal timing optimization models for DLT intersections applying the Monte Carlo method [26] and traffic progression method [27]. Others have investigated a dynamic and optimized method of traffic signal timing parameters to improve the integrated performance index of DLT intersections [28]. Besides, researchers have developed a left-hand excursion plane crossing design process [29]. Because of the increasing popularization of low-carbon travel in China, researchers have proposed a displaced left-turning bicycle lane based on the concept of a DLT lane [30]. Some scholars have put forward a new simplified DLT intersection (called CFI-Lite) on the basis of a DLT intersection and have verified its practicability [31]. Further, some scholars have made a comprehensive comparison of DLT intersections with other new type intersections with the operation and safety and have further explained the characteristics of DLT intersections [32]. Some researchers have investigated the coordination of consecutive DLT intersections under heterogeneous traffic conditions with a case study [33]. Other scholars have also evaluated alternative pedestrian and bicycle crossing schemes at continuous flow intersections [34]. There was a wealth of studies on the suitability, safety, and optimization of the DLT intersections.

However, the current design guidelines for unconventional DLT intersections were mostly from engineering experience and mathematical analysis methods [29]. They still lack detailed and specific guidance. At present, most of the studies on DLT intersections are about its applicability and performance or put forward the formula of queue length and delay on the basis of experience regression analysis. The design of intersections usually needs to take into account functions, such as traffic efficiency, safety, and environmental protection. Studies on considering the multifactor design method of reconstructing unconventional DLT intersections are still insufficient. The analytic hierarchy process (AHP) is often used to solve the multiobjective and comprehensive evaluation problem of the current engineering field. But this involves the participation of human factors, which is often controversial. The entropy method is a weighting method utilizing objective data and has been applied to the field of scientific research. Focused on this, this paper proposes a DLT lane lengths' analysis and evaluation model based on the entropy method that can be used to guide the design. The usage of simulation analysis in models is an important scientific research method $[35,36]$. Since VISSIM and SSAM are simulation software that have a wide range of applications in engineering and research [37-39], they have been applied to this design model. Taking an urban arterial road intersection in Xi'an as a case study, the proposed model is exactly applied to test its advancement, rationality, and practicability. 
Xi'an, the capital of Shaanxi Province, is also one of the top five cities in China in the 2020 Commuter Peak Congestion Index. Therefore, this paper takes an intersection on an urban arterial road with a high left-turning traffic volume as a case study. Built on the current form of intersections, a new intersection with DLT lanes on the outside of the intersection is proposed, which includes the gradual widening of the intersection. In addition, different DLT lane lengths are proposed to be improved by using equal-length intervals.

The remainder of this paper is arranged as follows: Section 2 introduces the DLT lane length evaluation and analysis model based on the entropy method that can provide guidance for intersection reconstruction design. Section 3 shows the case study about an intersection on urban arterial roads in Shaanxi Xi' an and outlines the model calibration. Then, Section 4 provides the sensitivity analysis of the VISSIM simulation and explains the scheme evaluation and comparison. Last but not least, Section 5 puts forward the research conclusions of this paper.

\section{Model}

The purpose of this paper is to come up with a new evaluation and analysis model for the reconstruction of added DLT lanes intersection. It can make the design scientific and help the designers to determine the appropriate length of the externally increased DLT lanes.

2.1. Preliminaries. Before the establishment of the model, specific requirements should be put forward for the actual engineering conditions to which the model is applicable. The prerequisites for using the model are as follows:

(i) Reconstruction of urban road intersection project and enough space for reconstruction

(ii) The number of added DLT lanes is the same as the number of left-turn lanes at the existing intersection, so the impact caused by changes in the number of lanes can be ignored

(iii) Regarding the independent urban cross intersection, the distance from the adjacent intersection upstream and downstream is large enough, and coordinated control is not considered

2.2. Entropy Method. In the process of analysis and calculation, how to operate a unified standard comparison to select the recommended length scheme is an essential issue that must be solved. And, this involves a scientific comparison between multiple parameters and multiple data.

The analytic hierarchy process (AHP), which is widely used in multiple parameters' comparison, is one of the weight evaluation methods. This includes expert scoring. However, the expert scores to determine the weight of indicators mainly rely on the subjective judgment of experts, which is controversial. In order to avoid this problem, the model in this paper adopts the entropy evaluation method (EEM) to calculate the weight.
The EEM is an effective method to solve multiparameter and multidata processing problems objectively. It comes from the concept of information entropy. Information entropy describes the average amount of information on the data, which means the more chaotic the system and the greater the amount of information carried. Comparing with other common weight calculation methods, the EEM cannot only realize the comparison of multiple parameters and multiple data between different schemes but also avoids the controversy caused by the participation of human factors. And, the EEM has been widely employed in many scientific fields such as electrical engineering [40], environment engineering [41], and water conservancy projects [42]. Therefore, the EEM is applied to the model in this paper as an important part.

The specific calculation process with EEM is as follows:

$$
\begin{aligned}
A & =A_{n \times k}, \\
B & =B_{n \times k}, \\
G & =G_{n \times k},
\end{aligned}
$$

where $A, B$, and $G$ represent the three different indexes, respectively, $n$ means the total number traffic volume combination, and $k$ represents the total scheme number. First, the same index of all the evaluated schemes should be converted into a matrix. Then, we take processing $A$ matrix as an example.

Matrix $A$ contains $n \times k$ simulation results ( $i$ represents the traffic volume combination number; $j$ represents the scheme number):

$$
A=\left[\begin{array}{cccc}
A_{1}(1) & A_{2}(1) & \cdots & A_{k}(1) \\
A_{1}(2) & A_{2}(2) & \cdots & A_{k}(2) \\
\vdots & \vdots & A_{j}(i) & \vdots \\
A_{1}(n) & A_{2}(n) & \cdots & A_{k}(n)
\end{array}\right] .
$$

Then, the best value of each row in matrix $A$ is selected (the smaller the value of the index one, the better the performance, so the minimum value of each row is selected as the optimal. On the contrary, the larger the value, the better, so the maximum value of each row is selected). For instance, if the value in the $A$ index is smaller, the better, then the minimum value of each row in the $A$ matrix is the best. Therefore, a new matrix $A_{m}$ is generated as follows:

$$
A_{m}=\left[\begin{array}{c}
\min A_{j}(1) \\
\min A_{j}(2) \\
\vdots \\
\min A_{j}(n)
\end{array}\right], \quad j=1 \text { to } k .
$$

The rest of the evaluation index matrices also repeat the above process:

$$
\left\{\begin{array}{l}
A_{m}(i)=\min A_{j}(i), \\
B_{m}(i)=\min B_{j}(i), \\
G_{m}(i)=\min G_{j}(i) \\
i=1 \text { to } n, j=1 \text { to } k .
\end{array}\right.
$$


The third step is to combine the above matrices into an overall matrix $M$ with $n$ rows and $p$ columns, and the weight of each index can be calculated:

$$
M=\left[\begin{array}{ccc}
A_{m}(1, j) & B_{m}(1, j) & G_{m}(1, j) \\
A_{m}(2, j) & B_{m}(1, j) & G_{m}(1, j) \\
\vdots & \vdots & \vdots \\
A_{m}(n, j) & B_{m}(1, j) & G_{m}(1, j) \\
& j=1 \text { to } k &
\end{array}\right]
$$

Each element in the matrix $M$ can be expressed as

$$
M=\left[\begin{array}{ccc}
m_{11} & m_{12} & m_{13} \\
m_{21} & m_{22} & m_{23} \\
\vdots & \vdots & \vdots \\
m_{n 1} & m_{n 2} & m_{n 3}
\end{array}\right] .
$$

The column vector in matrix $M$ is represented as

$$
m_{j}=\left[m_{1 t}, m_{2 t}, \ldots, m_{k t}\right]^{T}, \quad t=1,2, \ldots, q,
$$

where $q$ denotes the total number of the index type:

$$
M=\left[m_{1}, m_{2}, \ldots, m_{q}\right] .
$$

Units for the different indexes in the matrix $M$ are not the same. To further use the entropy method to process the data, all values should be standardized before the next step because the various indexes are not uniform. The absolute value is converted to the relative value to solve the normalization problem of the different property indexes. The specific calculation is as follows:

$$
m_{i t}^{\prime}=\frac{m_{i t}-\min \left\{m_{1 t}, \ldots, m_{n t}\right\}}{\max \left\{m_{1 t}, \ldots, m_{n t}\right\}-\min \left\{m_{1 t}, \ldots, m_{n t}\right\}},
$$

where $m_{i t}^{\prime}$ represents the normalization value.

In equation (9), the greater the gap between the indexes $m_{i t}$, the greater the effect of $m_{i t}$. On the contrary, if the index value is the same as another, it means that the index value had no influence on the final evaluation.

We obtain the new matrix $M^{\prime}$ for the forward procession:

$$
M^{\prime}=\left[\begin{array}{ccc}
m_{11}^{\prime} & m_{12}^{\prime} & m_{13}^{\prime} \\
m_{21}^{\prime} & m_{22}^{\prime} & m_{23}^{\prime} \\
\vdots & \vdots & \vdots \\
m_{n 1}^{\prime} & m_{n 2}^{\prime} & m_{n 3}^{\prime}
\end{array}\right] .
$$

The weight of index $j$ of scheme $i$ is calculated as follows:

$$
p_{i t}=\frac{m_{i t}^{\prime}}{\sum_{i=1}^{n} m_{i t}^{\prime \prime}}, \quad i=1 \text { to } n, t=1 \text { to } 3 .
$$

The entropy value of index $j$ is calculated as follows:

$$
e_{t}=-h \sum_{i=1}^{n} p_{i t} \ln \left(p_{i t}\right)
$$

where $h=1 / \ln (n)$ and satisfies $e_{t} \geq 0$. The entropy redundancy is calculated as follows:

$$
d_{t}=1-e_{t} \text {. }
$$

The weights of each index are calculated as follows:

$$
p_{t}=\frac{d_{t}}{\sum_{t=1}^{3} d_{t}}
$$

The weights of all indices are calculated and denoted as row vector $W$ :

$$
W=\left[p_{1}, p_{2}, p_{3}\right]
$$

2.3. Process of the Model. The specific content of the model purposed in this paper is shown in Figure 1:

The evaluation and analysis model of the reconstructed urban intersections with added DLT lanes consists of three parts. The first part is collecting existing intersection data. The collected data are mainly divided into two categories: traffic data and geometry of existing intersection. Traffic data is the basic functional goal that the new type of intersection must achieve, and the geometry of an intersection is the basic engineering condition for the reconstruction.

The second part is to design improved schemes and obtain various evaluation parameters of existing and improved intersection schemes. PTV VISSIM is widespread in the field of microscopic traffic simulation, and SSAM is officially designated by the Federal Highway Administration (FHWA) as the agency's safety evaluation software [43, 44]. The SSAM is a safety analysis software and classic in traffic simulation. At the same time, it can be compatible with the vehicle trajectory file obtained by VISSIM simulations and can evaluate the safety situation in the simulation process by identifying and analyzing the vehicle trajectory. In addition, the SSAM software also has built-in statistical analysis functions based on the frequency and severity of conflicts, which can help designers design safe transportation facilities. During this part, PTV VISSIM and SSAM software are used to construct simulation models of traditional intersections and improved schemes for simulation experiments.

Finally, the last part is sensitivity analysis and schemes' evaluation. The collected traffic volume is the traffic volume of the existing intersection for a limited period of time, and the actual traffic volume is constantly evolving. Therefore, it is necessary to simulate the performance of various traffic volume combinations and analyze and compare the performance of each scheme.

The calculation of the scheme evaluation is as follows:

From the matrix of equation (5), we can extract the scheme number $j$ of each element to generate a new matrix $J$ :

$$
J=\left[\begin{array}{ccc}
j_{11} & j_{12} & j_{13} \\
j_{21} & j_{22} & j_{23} \\
\vdots & \vdots & \vdots \\
j_{n 1} & j_{n 1} & j_{n 1}
\end{array}\right]
$$

Corresponding to each combination of traffic volume (each row), the score of each scheme can be calculated. 


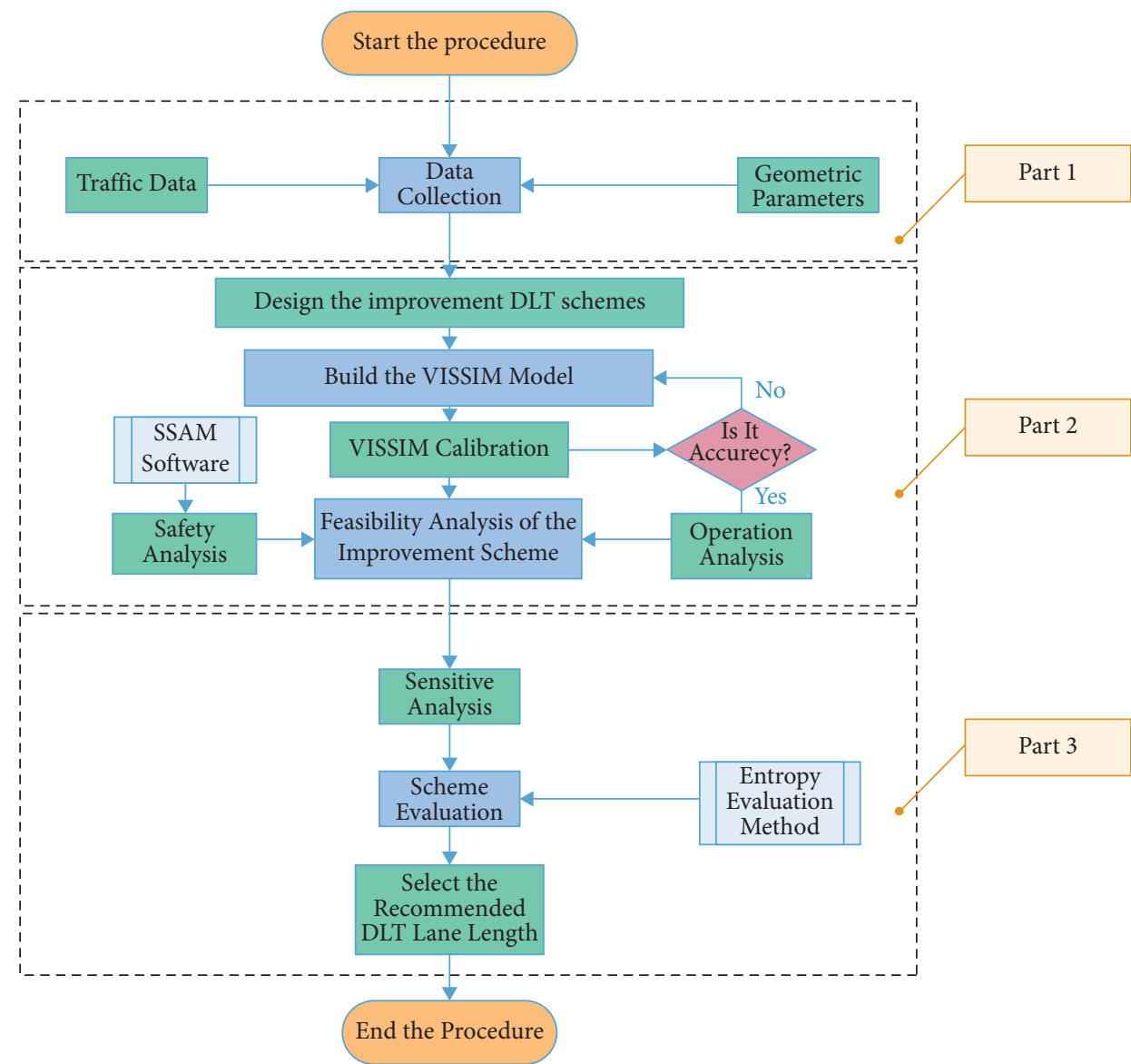

Figure 1: The flowchart of the evaluation and analysis model based on entropy evaluation method for the design process.

Taking the score of Scheme 1 as an example, the calculation is as follows:

$$
x_{i 1}= \begin{cases}\sum_{t=1}^{3} p_{t} \cdot j_{1 t}, & j_{1 t}=1, \quad i=1,2,3, \ldots, n, \\ 0, & j_{1 t} \neq 1 .\end{cases}
$$

After calculating the score results of $k$ schemes under $n$ traffic volume conditions, we can generate a new matrix $X_{n \times k}$, as shown below:

$$
X=\left[\begin{array}{cccc}
x_{11} & x_{12} & \cdots & x_{1 k} \\
x_{21} & x_{22} & \cdots & x_{2 k} \\
\vdots & \vdots & x_{i j} & \vdots \\
x_{n 1} & x_{n 2} & \cdots & x_{n k}
\end{array}\right] .
$$

Extract each row vector in matrix $X$ as $x_{i}$ :

$$
x_{i}=\left[x_{i 1}, x_{i 2}, \ldots, x_{i k}\right] .
$$

Record the column with the highest score in each row vector as $r_{i}$ :

$$
r_{i}=j \text {, if } x_{i j}=\max \left\{x_{i}\right\}, \quad j=1,2, \ldots, k .
$$

Finally, the column vector $R$ of the recommended optimal length scheme under $n$ different traffic volume conditions can be obtained:

$$
R=\left[r_{1}, r_{2}, \ldots, r_{n}\right]^{T} .
$$

\section{Case Study}

In this part, we introduce the process and methodology of the case study in this paper.

3.1. Problem Statement. Xi'an, as an ancient capital with a thousand years of history, has become one of the cities with the most serious traffic problems in China. With the continuous development of modernization and urbanization, the number of vehicles of Xi'an city has continued to rise. According to China's congestion rankings on 2020 by Baidu map, Xi'an city is the fourth of this rank. Relieving the congestion problem of the intersections in Xi'an has the essential reference for other cities.

The focus is on an intersection of Xi' an city. As shown in Figure 2, the intersection is located where Electronic Road and Taibai South Road meet; as can be seen, this is the junction of two major arteries in Xi'an city. This junction consists of a signalized intersection. And, there is a lot of left- 


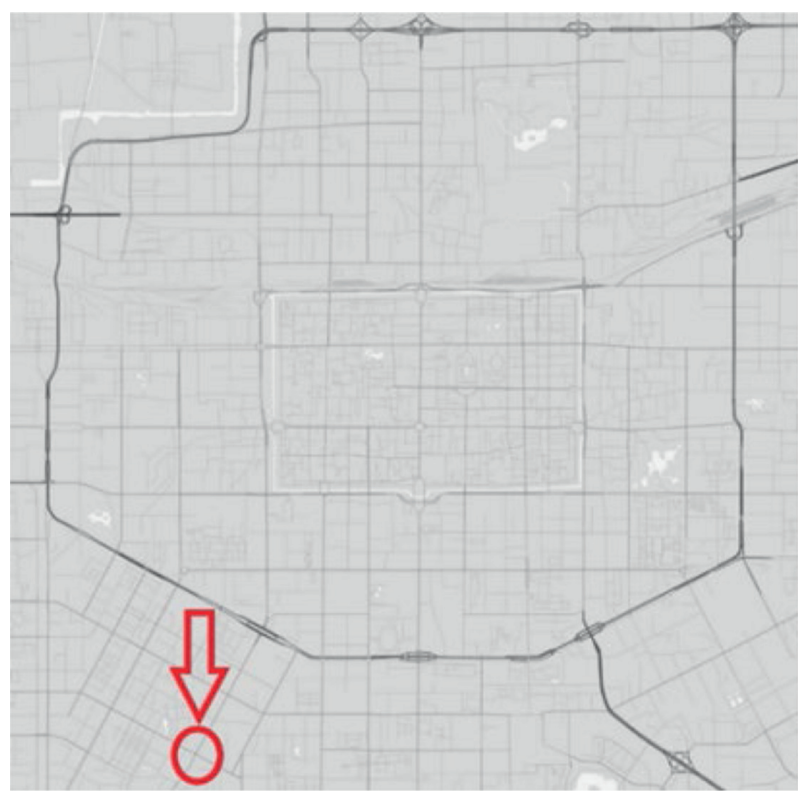

Figure 2: The location of the investigated intersection. The investigated intersection is a traditional cross intersection.

turning traffic at this intersection, especially in the east-west direction.

Left-turning traffic has always been an essential issue of efficiency and safety at intersections. Thus, we focused on the left-turning traffic problem at this intersection in the eastwest direction. Because of the heavy left-turning traffic of this intersection, the left-turning traffic flows from the east and west entrances often have high delays when passing intersections. It takes a lot of time for drivers to go through the intersection, especially during the evening rush hour. The manner in which to improve the operation of leftturning traffic flows at this intersection has become a problem that urgently needs to be solved.

3.2. Data Collection. Figure 3 shows the present intersection of Taibai South Road and Electronic Road in Xi'an. The traffic volume of left-turning traffic in the east-west direction is very high, especially in the evening rush hours. Leftturning vehicles in the east-west direction queue for a long time when passing through the intersection. At this intersection, the speed limit for the basic section in the east-west direction is $70 \mathrm{~km} / \mathrm{h}$ and for the basic section in the northsouth direction is $60 \mathrm{~km} / \mathrm{h}$. The east entrance of the intersection has five lanes from east to west, and there are four lanes from west to east; the west entrance of the intersection has five lanes from west to east and three lanes from east to west. There are collector-distributor lanes on both sides. The north entrance has five lanes from north to south and three lanes from south to north; meanwhile, the south entrance has five lanes from south to north and three lanes from north to south. The width of each lane is $3 \mathrm{~m}$.

Step 1. Selecting data collection time.

Figure 4 shows a 24 -hour traffic congestion coefficient map of Xi'an on 21 October 2020, indicating the peak and low-traffic periods of the day. It can be seen from the figure that the morning peak time was from 7:00 a.m. to 9:00 a.m., while the evening peak time was from 5:00 p.m. to 7:00 p.m., and the noon trough time was from 11:00 a.m. to 1:00 p.m. The experimental data were collected in one hour during the morning and evening peak and midday trough periods.

Step 2. Preparing experimental equipment.

Data collection required the use of Unmanned Aerial Vehicles (UAV), mobile phones, radars, laptops, radar data and power cables, a drone battery and a controller, and a mobile power supply (for radar and laptop charging).

Step 3. Choice of instrument installation position.

As shown in Figure 5, when measuring the speed of vehicles, in order to ensure that the speed of each lane of the entrance in each direction of the intersection could be measured as accurately as possible, the installation of the radar should be very close to the direction of the vehicles, and the erection position on the roadside should be as high as possible. The height of the radar should exceed $2 \mathrm{~m}$ to ensure that there are no fixed obstacles in the measurement range; when there was a suitable overpass near the intersection, it was best to measure the vehicle directly on the overpass.

Step 4. Specific experimental operations.

First, we turned on the remote control of the drone; then, the drone should be turned on. The power cord of the radar and laptop were connected to the mobile power supply to ensure normal power supply, and the data cable of the radar was inserted into the USB port of the laptop. Then, the following items were clicked on in sequential order: "Check" to see if the radar is working properly, "Settings" to synchronize the time of the radar and the notebook, and the original data to delete it. Finally, the investigation could be started, and the radar would officially begin to measure data.

Step 5. Inspecting during data collection.

During the radar data collection period, the real-time inspection interface of the software open should always be retained, and the radar measurement should be checked every 5 mins to ensure it is normal.

Step 6. Processing analysis.

When the data collection was finished, the data were downloaded as a spreadsheet with a designated name, and the video data taken by the drone were copied. Tables 1-3 show the traffic volume data during the morning, midnoon, and evening periods. As shown in the table, in the evening rush hour, the east-west entrance left-turn traffic has the highest proportion and is the most congested period of urban traffic.

3.3. Design of Improvement DLTS Schemes. Left-turning traffic flows at intersections often conflict with oncoming direction traffic flows. To improve the efficiency of left-turning traffic in the east-west direction, adding DLT lanes is one of the 


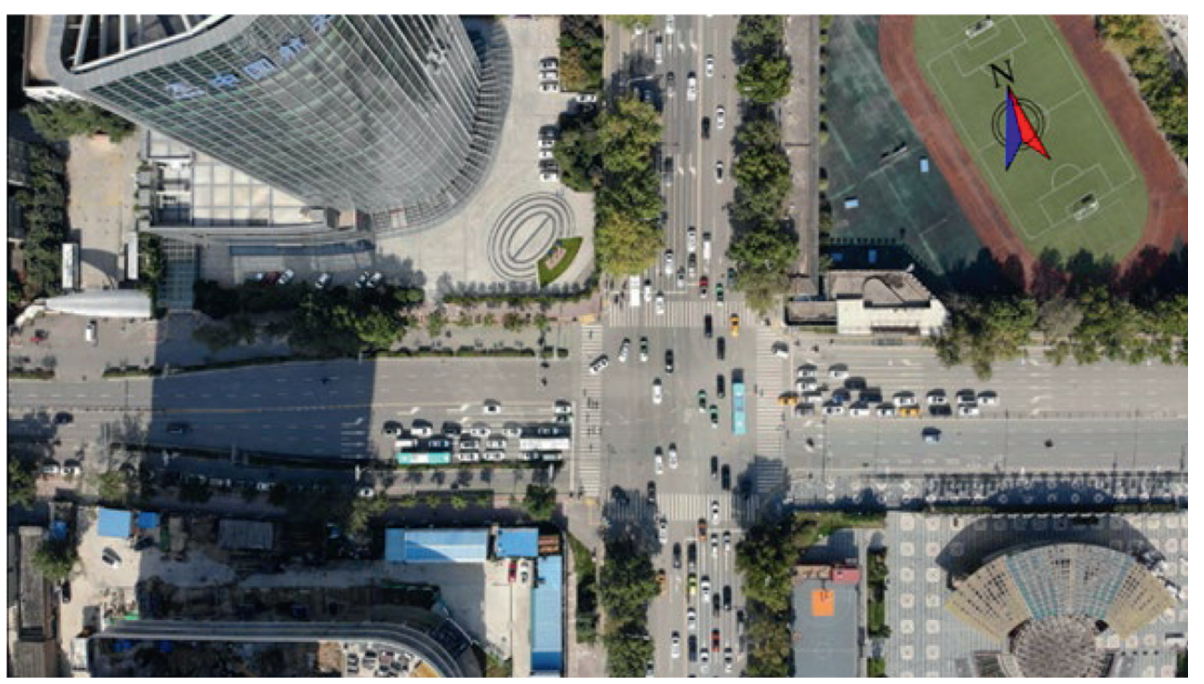

FIgURE 3: The actual situation of the investigated intersection. The investigated intersection is located in the center of Xi'an Yanta district. The east-west street is Dianzi Road, and the north-south street is Taibai South Road.

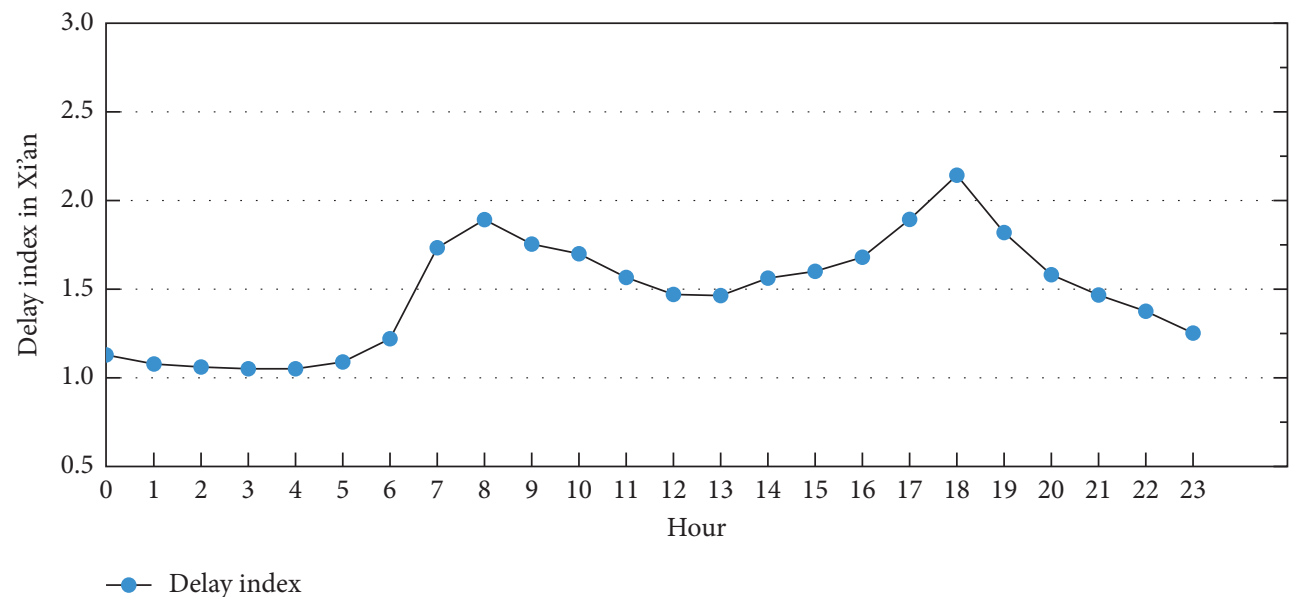

FIgURE 4: The congestion index in Xi'an on 2020.10.21. The real-time congestion index can be gathered from Autonavi Company web page at https://report.amap.com/detail.do?city $=610100$.

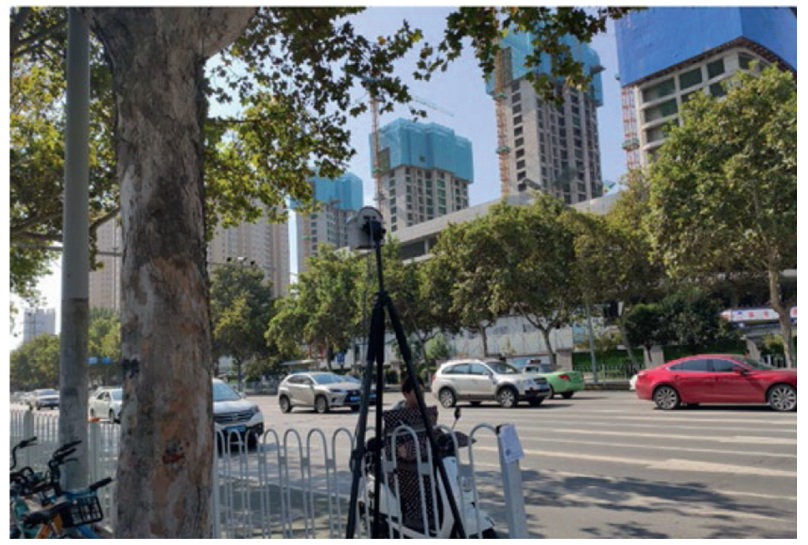

FIGURE 5: The radar survey at the intersection. This figure was taken at $34.2174^{\circ} \mathrm{N}, 108.9125^{\circ} \mathrm{E}$. The figure shows the radar erect at the south entrance of the intersection. When measuring, the radar speed measurement direction must be as parallel as possible to the driving direction of the vehicles and facing the front of the vehicles and must the same for the other three entrances. effective solutions. Advanced design schemes for extending the DLT lanes on the outside of the current east-west entrance were put forward in this paper.

As shown in Figure 6, the specific design method of the advanced schemes with added DLT lanes is as follows:

(i) Survey and collect the design data and construction parameters of existing intersections, including the number of lanes, lane width, transition section length, and existing signal timing plans. Figure 6(a) shows the existing intersection. There is a $60 \mathrm{~m}$ long transition section at the west entrance. Both the east entrance and the west entrance include two left-turn lanes. According to the usage conditions of the model, the above parameters are consistent with the status quo.

(ii) As shown in Figure 6(b), keep the number of basic lanes and the number of left-turn lanes at the existing intersection unchanged, and change the 
TABLE 1: Collected data during the peak hour of 8:00 a.m. to 9:00 a.m. on 21 October 2020.

\begin{tabular}{|c|c|c|c|c|c|c|c|c|}
\hline & Flow & Flow number & Car (veh/h) & Truck (veh/h) & Bus (veh/h) & Max speed $(\mathrm{km} / \mathrm{h})$ & $\begin{array}{c}\text { Min speed } \\
(\mathrm{km} / \mathrm{h})\end{array}$ & $\begin{array}{c}\text { Average speed } \\
(\mathrm{km} / \mathrm{h})\end{array}$ \\
\hline \multirow{3}{*}{ East entrance } & Through & 1 & 546 & 12 & 42 & 60 & 0 & 19 \\
\hline & Left turn & 2 & 366 & 12 & 6 & 84.5 & 0 & 25 \\
\hline & Right turn & 3 & 84 & 0 & 36 & 62 & 0 & 21.5 \\
\hline \multirow{3}{*}{ West entrance } & Through & 4 & 708 & 0 & 48 & 63 & 0 & 22 \\
\hline & Left turn & 5 & 372 & 0 & 0 & 69 & 0 & 29 \\
\hline & Right turn & 6 & 84 & 0 & 0 & 62.8 & 0 & 24 \\
\hline \multirow{3}{*}{ South entrance } & Through & 7 & 1458 & 24 & 48 & 52.4 & 0 & 12 \\
\hline & Left turn & 8 & 132 & 6 & 0 & 46 & 0 & 23 \\
\hline & Right turn & 9 & 246 & 6 & 0 & 50 & 0 & 13 \\
\hline \multirow{3}{*}{ North entrance } & Through & 10 & 1554 & 12 & 48 & 58.5 & 0 & 18 \\
\hline & Left turn & 11 & 150 & 0 & 18 & 50 & 0 & 25 \\
\hline & Right turn & 12 & 294 & 6 & 0 & 53.5 & 0 & 18.5 \\
\hline
\end{tabular}

TABLE 2: Collected data during the peak hour of 11:00 a.m. to 12:00 a.m. on 21 October 2020.

\begin{tabular}{|c|c|c|c|c|c|c|c|c|}
\hline & Flow & Flow number & Car $($ veh/h) & Truck (veh/h) & Bus (veh/h) & Max speed $(\mathrm{km} / \mathrm{h})$ & $\begin{array}{l}\text { Min speed } \\
(\mathrm{km} / \mathrm{h})\end{array}$ & $\begin{array}{l}\text { Average speed } \\
\qquad(\mathrm{km} / \mathrm{h})\end{array}$ \\
\hline \multirow{3}{*}{ East entrance } & Through & 1 & 332 & 21 & 28 & 62 & 0 & 18 \\
\hline & Left turn & 2 & 282 & 21 & 7 & 83.5 & 0 & 25 \\
\hline & Right turn & 3 & 233 & 14 & 28 & 64 & 0 & 20 \\
\hline \multirow{3}{*}{ West entrance } & Through & 4 & 600 & 56 & 49 & 60 & 0 & 24.5 \\
\hline & Left turn & 5 & 268 & 0 & 0 & 70 & 0 & 30 \\
\hline & Right turn & 6 & 106 & 21 & 0 & 62.6 & 0 & 25 \\
\hline \multirow{3}{*}{ South entrance } & Through & 7 & 1956 & 49 & 57 & 52.2 & 0 & 9.9 \\
\hline & Left turn & 8 & 148 & 0 & 0 & 48 & 0 & 22 \\
\hline & Right turn & 9 & 282 & 21 & 0 & 51 & 0 & 13 \\
\hline \multirow{3}{*}{ North entrance } & Through & 10 & 2196 & 49 & 71 & 56.5 & 0 & 17.9 \\
\hline & Left turn & 11 & 268 & 7 & 21 & 52 & 0 & 24.5 \\
\hline & Right turn & 12 & 226 & 0 & 7 & 54.5 & 0 & 18 \\
\hline
\end{tabular}

TABLE 3: Collected data during the peak hour of 5:00 p.m. to 6:00 p.m. on 21 October 2020.

\begin{tabular}{|c|c|c|c|c|c|c|c|c|}
\hline & Flow & Flow number & Car (veh/h) & Truck (veh/h) & Bus (veh/h) & Max speed $(\mathrm{km} / \mathrm{h})$ & $\begin{array}{l}\text { Min speed } \\
(\mathrm{km} / \mathrm{h})\end{array}$ & $\begin{array}{c}\text { Average speed } \\
(\mathrm{km} / \mathrm{h})\end{array}$ \\
\hline \multirow{3}{*}{ East entrance } & Through & 1 & 474 & 20 & 60 & 54 & 0 & 18.7 \\
\hline & Left turn & 2 & 294 & 7 & 0 & 63.7 & 0 & 26.6 \\
\hline & Right turn & 3 & 160 & 20 & 27 & 56 & 0 & 21.7 \\
\hline \multirow{3}{*}{ West entrance } & Through & 4 & 787 & 20 & 47 & 61.2 & 0 & 29.5 \\
\hline & Left turn & 5 & 313 & 13 & 0 & 70.6 & 0 & 37 \\
\hline & Right turn & 6 & 133 & 7 & 0 & 63 & 0 & 31.5 \\
\hline \multirow{3}{*}{ South entrance } & Through & 7 & 1481 & 47 & 87 & 22.7 & 0 & 9 \\
\hline & Left turn & 8 & 100 & 7 & 7 & 29.9 & 0 & 21.6 \\
\hline & Right turn & 9 & 253 & 7 & 0 & 24 & 0 & 12 \\
\hline \multirow{3}{*}{ North entrance } & Through & 10 & 1661 & 67 & 67 & 46.8 & 0 & 15.1 \\
\hline & Left turn & 11 & 220 & 0 & 40 & 54 & 0 & 20.16 \\
\hline & Right turn & 12 & 253 & 0 & 0 & 48 & 0 & 17.2 \\
\hline
\end{tabular}




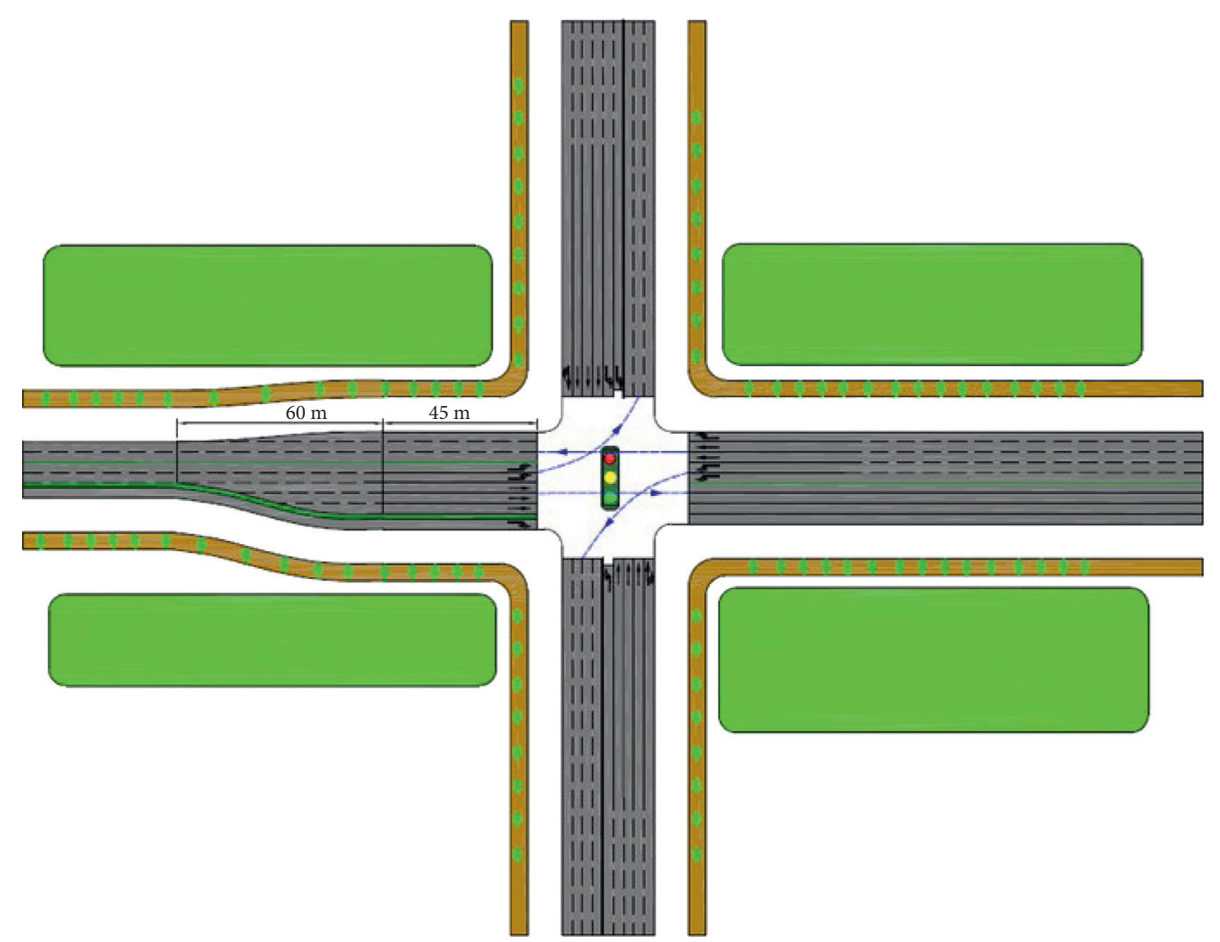

(a)

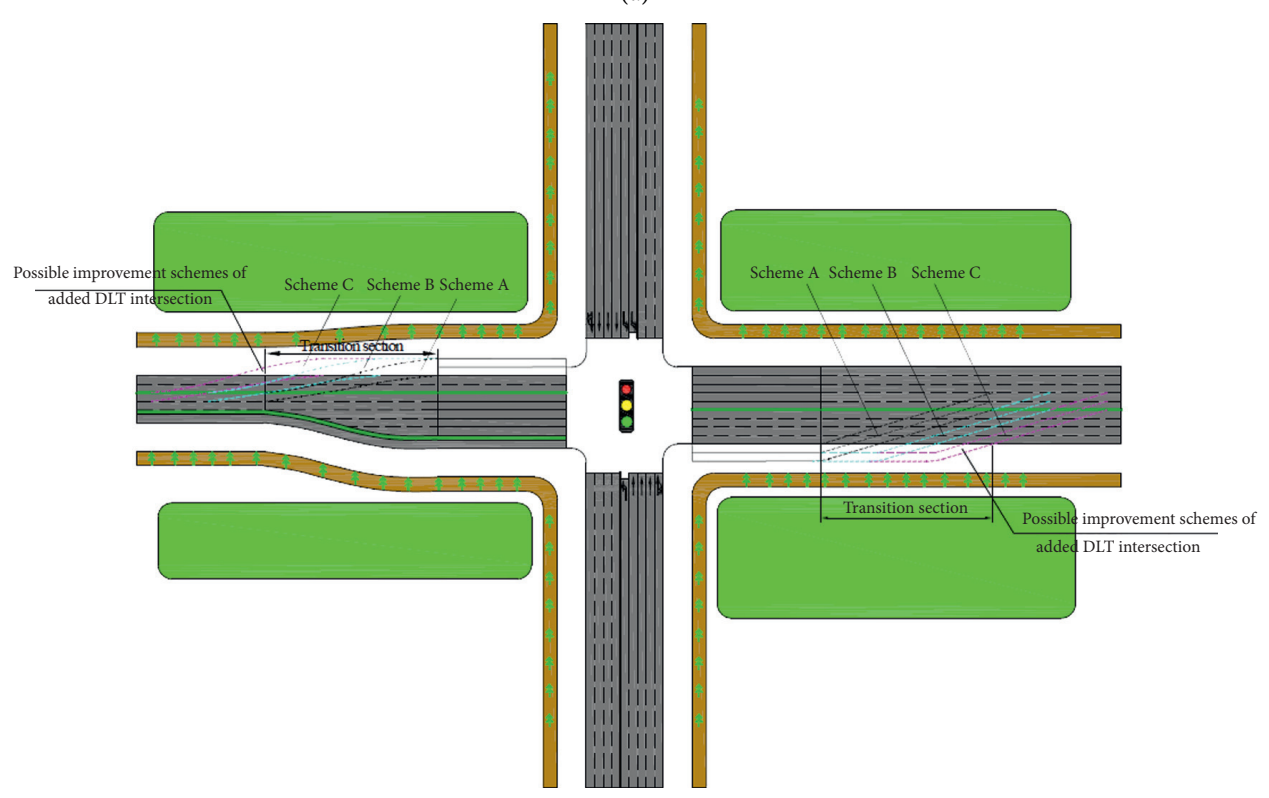

(b)

Figure 6: Continued. 


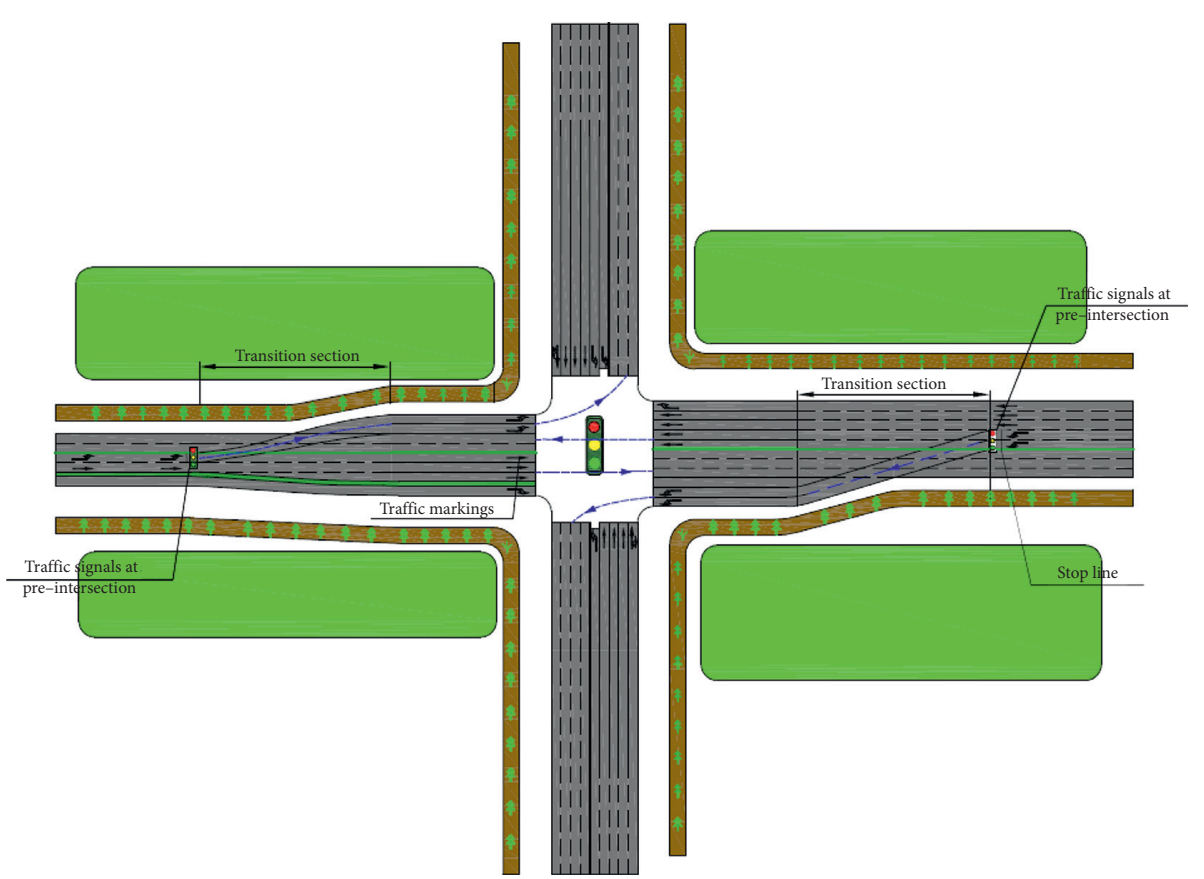

(c)

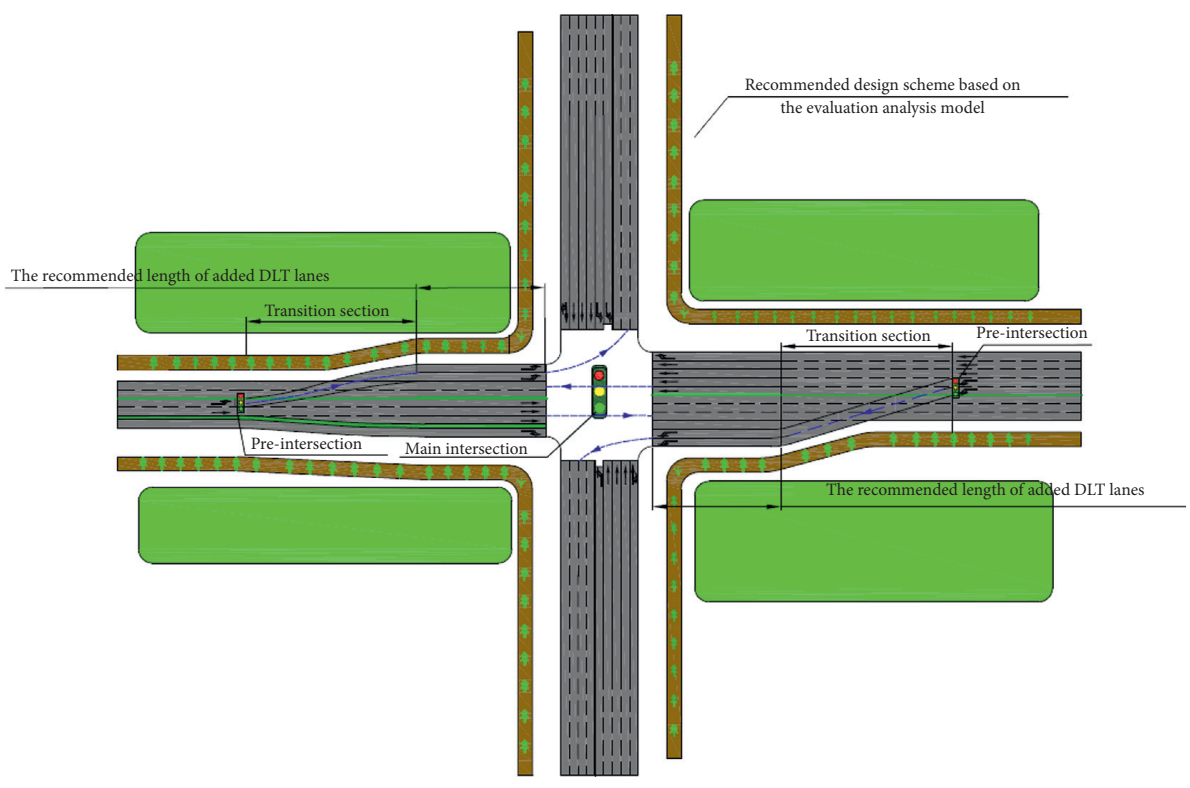

(d)

Figure 6: The design method of the DLT scheme. (a) Existing traditional situation. (b) Put forward some possible improvement schemes. (c) Traffic facilities design. (d) Determine the final recommended design scheme.

left-turn lanes at the original entrance to allow through vehicles to pass. Then, add DLT lanes to the outside of the opposite straight lanes, and set a smooth transition section to ensure a reasonable transition. After that, put forward some possible improvement reconstruction schemes according to the actual land conditions and the length of the existing left-turn lane.

(iii) Complete the design of traffic facilities for each possible improvement scheme, including the design of traffic signs and markings, main intersection signal timing, and preintersection signal timing. This safeguards that the vehicles can safely and smoothly pass through the intersection (Figure 6(c)).

(iv) Analyze the operation and safety of possible improvement schemes and the existing intersection. Then, the sensitivity analysis and evaluation of possible improvement schemes by using the evaluation and analysis model based on the entropy 
evaluation method are carried out. Finally, the recommended design scheme with the recommended length of the extra DLT lane is obtained (Figure 6(d)).

The results of simulation experiments for each scheme are shown in Figure 7.

In the case study of this paper, there were two DLT lanes at the east entrance and also two at the west entrance. It kept the number of DLT lanes consistent with the left-turn lanes in the current situation. The main variable included in this study was the length of the DLT lanes. The present length of the entrance was $45 \mathrm{~m}$, while the longest length that could be expanded at this stage was $145 \mathrm{~m}$. The lengths of the DLT lanes in schemes $1-5$ changed at equal intervals, which are $45,70,95,120$, and $145 \mathrm{~m}$.

After adding DLT lanes at the intersection, was it effective? If there were improvements in some fields, what were the percentages of advancement? What was the recommended length of the DLT lanes on the operating conditions? To solve these problems, we used the entropybased model proposed in this paper for definite evaluation and analysis.

3.4. VISSIM Calibration. The parameters of the VISSIM simulation model needed to be calibrated before the simulation of an intersection improved scheme, so as to assure the accuracy of the VISSIM simulation model. The specific calibration of the VISSIM model is as follows. First, the parameters were input into the VISSIM software according to the current field investigation at the intersection of South Taibai Road and Dianzi Road, such as operating speed and vehicle composition proportion. Next, we selected the governing car following model in VISSIM. The governing car following model is the classic model proposed by German Professor Wiedemann, which belongs to the psycho-physiological model. There are two types in the Wiedemann model by default: Wiedemann99 and Wiedemann74. Previous studies found that Wiedemann74 was more consistent with the vehicle behavior on urban roads, and the Wiedemann74 model was also selected for simulation in this study. After selecting the Wiedemann74 model, key parameters such as the average stopping distance and the desired time headway were modified, relying on the actual survey data. Then, the simulation was calibrated with the capacity indicators, which could comprehensively reflect the similarity between the effect of the whole simulation model and the actual intersection situation.

Then, the VISSIM simulation model was run 30 times under each circumstance, and the average value of the traffic volume of each inlet and direction was taken. Finally, the relationship between the traffic volume data obtained from the simulation and the traffic volume data obtained from the actual survey at the intersection was compared. The error was characterized by the mean absolute percent (MAPE) value. According to relevant studies, when the MAPE value of the traffic volume in each direction is less than $15 \%$, the simulation results of the VISSIM simulation model are considered to be effective. The MAPE was calculated as follows:

$$
\text { MAPE }=\frac{1}{q} \sum_{i=1}^{q}\left|\frac{C_{v}^{i}-C_{f}^{i}}{C_{f}^{i}}\right|,
$$

where $q$ denotes the 12 different flows in this study, $C_{v}^{i}$ is the capacity (number of vehicles crossing the intersection per unit time) simulated in the VISSIM model (veh/h), and $C_{f}^{i}$ is the capacity of the investigation (veh/h).

After running the realistic model of the intersection in VISSIM 30 times, the calculated results of the average hourly traffic volume, the actual collected traffic volume at the intersection, and the MAPE value are summarized in Table 4.

As shown in Table 4, the MAPE value of traffic flow in the 12 directions was $6.43 \%$ in total. Because the traffic volume error in total was less than $15 \%$, the constructed model met the requirements of simulation accuracy. Thus, the calibration accuracy of the VISSIM model was reasonable $[45,46]$.

3.5. Operation Analysis. The east-west direction is the main road. Because of the high volume of left-turning traffic during peak hours, it is also the direction for the implementation of the DLT schemes; the north-south direction is the secondary road, and the north-south direction remains the actual crossroad mouth form. It is the main development goal of the current intersection that increasing traffic capacity and improving delays. And, environmental protection is also one of the common goals of today's engineering projects. Therefore, the indexes selected in this case were the capacity, delays, number of stops, and NOx emissions.

Capacity refers to the number of vehicles passing through the entire intersection in a unit hour. Delays mean the difference between the actual travel time and the expected travel time. In this study, delays include stop delay and travel delay, and it is calculated as follows:

$$
D=d_{1}+d_{2}
$$

where $D$ denotes the total delay, $d_{1}$ denotes the stop delay, and $d_{2}$ denotes the travel delay. The number of stops indicates the average number of stops for each vehicle passing the intersection; NOx emissions represent the total amount of nitrogen oxide emitted by vehicles passing through the intersection within an hour. There were five groups of advanced models and one existing intersection model, and each group ran 30 random seeds to obtain more scientific and reliable results from the statistical significance. Therefore, 180 simulations were performed in the case of existing traffic volume. The results are stated below in Table 5 .

It was evident that, in the simulation results, Scheme 0 was much higher than the other situations in terms of the delays, number of stops, and NOx emissions. They all had a similar trend, with the degree of development gradually increasing from Scheme 1 to Scheme 4, but with no distinction when the improvement changes from Scheme 4 to Scheme 5. This indicated that the difference resulting from changing the length of the added DLT lanes had a regular influence on the results. However, the capacity for each 


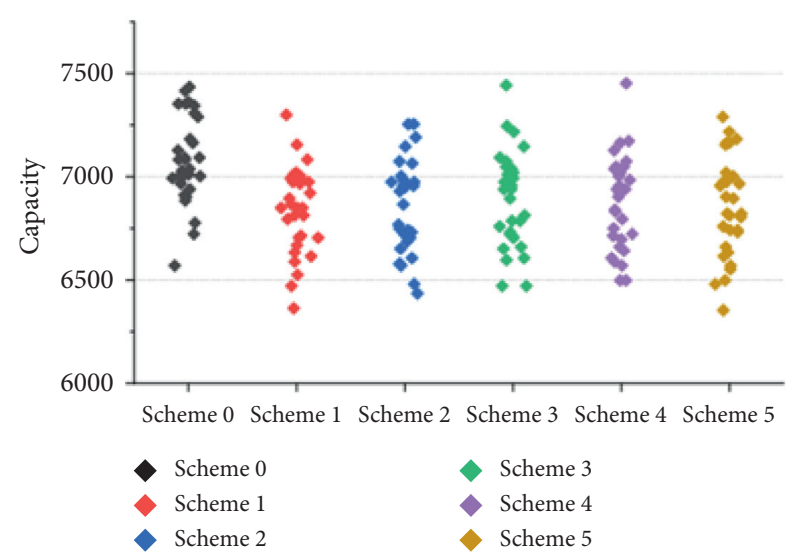

(a)

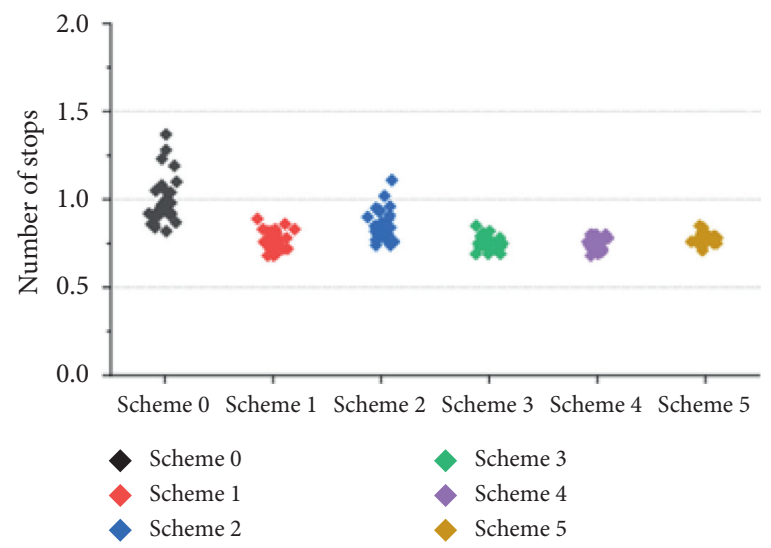

(c)

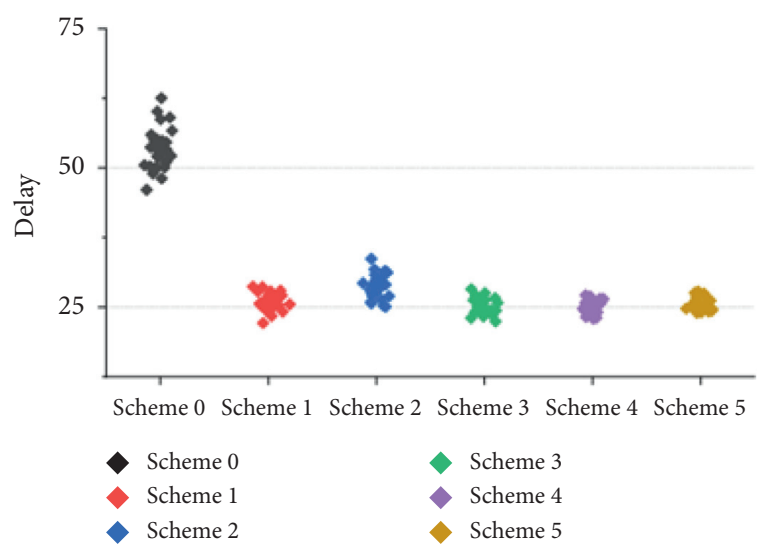

(b)

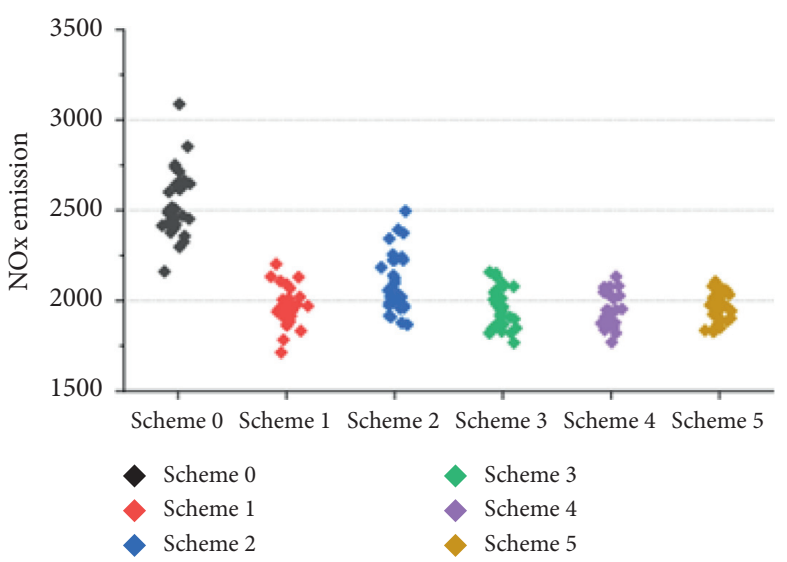

(d)

Figure 7: Simulation results of the experiments. (a) Capacity. (b) Delays. (c) Number of stops. (d) NOx emissions.

TABLE 4: VISSIM simulation calibration results with the collected data. MAPE, mean absolute percent.

\begin{tabular}{|c|c|c|c|c|}
\hline Flow number & Investigate capacity (veh/h) & Simulated capacity (veh/h) & Individual MAPE (\%) & Total MAPE (\%) \\
\hline$i=1$ & 554 & 486 & 12.27 & \multirow{12}{*}{6.43} \\
\hline$i=2$ & 301 & 270 & 10.30 & \\
\hline$i=3$ & 207 & 198 & 4.35 & \\
\hline$i=4$ & 847 & 756 & 10.74 & \\
\hline$i=5$ & 326 & 288 & 11.66 & \\
\hline$i=6$ & 140 & 144 & 2.86 & \\
\hline$i=7$ & 1615 & 1971 & 22.04 & \\
\hline$i=8$ & 114 & 108 & 5.26 & \\
\hline$i=9$ & 260 & 279 & 7.31 & \\
\hline$i=10$ & 1795 & 2088 & 16.32 & \\
\hline$i=11$ & 260 & 225 & 13.46 & \\
\hline$i=12$ & 253 & 288 & 13.83 & \\
\hline
\end{tabular}

scheme did not differ between the six schemes. This meant there were no obvious advantages between the different schemes under the present investigated traffic volume.

3.6. Safety Analysis. A complete evaluation should conclude with both an operation and safety evaluation. With the calibration of VISSIM already completed, the microscopic vehicle simulation of the VISSIM model already has a high degree of agreement with the actual situation. We took the number of cross-conflicts present in the one-hour intersection vehicle operation video investigated under actual conditions and compared it with the safety simulation results. Then, we found that there were 4 cross-conflicts in the video. The deviation between simulation and reality was within the acceptable range. Therefore, the simulation results of SSAM were considered reliable.

The safety analysis was applied to the six schemes with evening peak hours' data. The results are shown below. 
TABLE 5: VISSIM results of the six selected schemes with evening peak hour data.

\begin{tabular}{|c|c|c|c|c|c|c|c|c|}
\hline \multirow{2}{*}{$\begin{array}{l}\text { Item } \\
\text { Scheme } 0\end{array}$} & \multicolumn{2}{|c|}{ Capacity (veh/h) } & \multicolumn{2}{|c|}{ Average delays (s) } & \multicolumn{2}{|c|}{ Number of stops } & \multicolumn{2}{|c|}{$\begin{array}{l}\text { NOx emission } \\
\text { (gallons/h) }\end{array}$} \\
\hline & 7083 & & 53.23 & & 0.99 & & 2543.31 & \\
\hline Scheme 1 & 6840 & $-3.43 \%$ & 25.9 & $51.34 \%$ & 0.77 & $22.22 \%$ & 1965.42 & $22.72 \%$ \\
\hline Scheme 2 & 6849 & $-3.30 \%$ & 28.74 & $46.01 \%$ & 0.85 & $14.14 \%$ & 2098.35 & $17.50 \%$ \\
\hline Scheme 3 & 6885 & $-2.80 \%$ & 25.24 & $52.58 \%$ & 0.76 & $23.23 \%$ & 1955.52 & $23.11 \%$ \\
\hline Scheme 4 & 6876 & $-2.92 \%$ & 25.02 & $53.00 \%$ & 0.75 & $24.24 \%$ & 1943.46 & $23.59 \%$ \\
\hline Scheme 5 & 6849 & $-3.30 \%$ & 25.46 & $52.17 \%$ & 0.77 & $22.22 \%$ & 1963.8 & $22.79 \%$ \\
\hline
\end{tabular}

Table 6 shows the results of the safety analysis of the six schemes, including the existing traditional scheme. The results show that compared to the new type of intersection with additional DLT lanes, the traditional intersection had significantly higher safety risks in the rear end and lane change. Compared to the proposed improvement plan, the value for the item "rear end" was 70\% 100\% higher, and the value for the item "lane change" was 100\% 200\% higher than the improvement plan. However, due to the subintersections set up at DLT intersections, the traditional intersections in the column of the crossing had advantages and their values were lower than the other five improved schemes. In general, the sum of the three potential safety risks shows that the improved DLT intersection scheme should outperform the existing traditional intersections in terms of safety performance. Moreover, the five improved schemes achieved relatively close safety effects.

\section{Results and Discussion}

4.1. Sensitivity Analysis. Sensitivity analysis can reflect the improvement ratio of each advancement scheme compared to the present scheme. Capacity, delays, number of stops, and NOx emissions are the four indexes. Based on the maximum capacity under different lane numbers in the Highway Capacity Manual (HCM) [47], multiplying by the certain coefficients, different traffic volume parameters were obtained. All volume parameters in VISSIM are shown in Table 7.

The next step was to calculate the signal timing plan. As Figure 8 shows, the signal timing of the existing intersection consists of four stages and the phasing of the improvement schemes consists of three stages. The added DLT lanes eliminate the conflicts between left-turning vehicles and straight vehicles at the main intersection, and the straight and left-turning vehicles on the same entrance at the main intersection can be released at the same time.

Synchro7 is a signal optimization software using the NEMA signal timing structure. We input the number of signal stages, the traffic volume of each direction, and lane allocation plan in synchro7; then, the synchro7 calculated and output the recommended signal timing plans. Afterward, we input the signal timing calculated by synchro7 into VISSIM.

For the development schemes of the different DLT lanes lengths, the improvements in the indicators between them and the present intersection scheme were compared and analyzed one by one. The DLT lane length was $45 \mathrm{~m}$ in
Scheme 1, $70 \mathrm{~m}$ in Scheme 2, $95 \mathrm{~m}$ in Scheme 3,120 $\mathrm{m}$ in Scheme 4, and $145 \mathrm{~m}$ in Scheme 5. And, the traditional intersection was represented as Scheme 0 .

Figure 9 shows the improvement in the capacity under the five development schemes. As shown in this picture when the traffic volume in the east-west direction was less than $1029 \mathrm{veh} / \mathrm{h}$, there was no obvious advancement effect of the five advanced schemes compared to the traditional cross intersection. When the east-west traffic volume continued to develop, the advantage of setting DLT lanes began to show. In Scheme 1, when the east-west traffic volume reached the maximum value of $3430 \mathrm{veh} / \mathrm{h}$ in the test process, the effect of improving the capacity was most obvious, reaching a maximum of $22 \%$. In Scheme 2, when the east-west traffic volume reached the maximum combined traffic volume of $3430 \mathrm{veh} / \mathrm{h}$, the enhancement effect peaked at $31.5 \%$. In the case of Scheme 3, as the input traffic volume in the east-west direction increased after exceeding $1029 \mathrm{veh} / \mathrm{h}$, the improvement rates also increased. In this simulation experiment, when the maximum combined traffic volume was $3430 \mathrm{veh} / \mathrm{h}$, the maximum percentage of the enhancement effect was able to reach $36 \%$. For Scheme 4 , the simulation results show that, with the growth of the traffic volume in the east-west direction after exceeding $1029 \mathrm{veh} / \mathrm{h}$, the advantages of the Scheme 4 became gradually clear. When the traffic volume in the east-west direction reached the maximum value of $3430 \mathrm{veh} / \mathrm{h}$, the maximum percentage of the improvement effect was able to reach $42 \%$. The maximum improvement percentage under Scheme 5 was 36\%, which was generated when the input traffic volume in the east-west direction was $3430 \mathrm{veh} / \mathrm{h}$ and the input traffic volume in the north-south direction was $3656 \mathrm{veh} / \mathrm{h}$.

In summary, there was no improvement in the capacity of all five development schemes in the case of low traffic in the east-west direction. When the traffic volume was greater than $1029 \mathrm{veh} / \mathrm{h}$, the enhancement effect gradually increased as the traffic volume increased. From Scheme 2 to Scheme 5, as the lengths of the DLT lanes increased, the maximum improvement effect of the capacity gradually increased, while in terms of the change from Scheme 4 to Scheme 5, as the lengths of the DLT lanes increased from 120 to $145 \mathrm{~m}$, the maximum advancement effect of the capacity slightly reduced.

Figure 10 shows the advance in the average vehicle delay index under the five scenarios. In the case of Scheme 1, the average vehicle delay upgrade ratios were concentrated between $5 \%$ and $30 \%$ and the maximum improvement percentage was $31 \%$. In Scheme 2, the average delay upgrade 
TABLE 6: Safety analysis of the six simulations by the surrogate safety assessment model (SSAM).

\begin{tabular}{|c|c|c|c|c|c|}
\hline Scheme number & Item & Crossing & Rear end & Lane change & Total \\
\hline 0 & Present intersection & 5 & 120 & 52 & 177 \\
\hline 1 & DLT $45 \mathrm{~m}$ & 9 & 69 & 25 & 103 \\
\hline 2 & DLT $70 \mathrm{~m}$ & 15 & 71 & 19 & 105 \\
\hline 3 & DLT $95 \mathrm{~m}$ & 12 & 60 & 20 & 92 \\
\hline 4 & DLT $120 \mathrm{~m}$ & 8 & 63 & 19 & 90 \\
\hline 5 & DLT $145 \mathrm{~m}$ & 13 & 65 & 17 & 95 \\
\hline
\end{tabular}

TABLe 7: The traffic volume combinations of the sensitivity analysis (veh/h).

\begin{tabular}{lc}
\hline Item & Value \\
\hline East/west volume & $686 / 1029 / 1372 / 1715 / 2058 / 2401 / 2744 / 3087 / 3430$ \\
North/south volume & $1828 / 2285 / 2742 / 3199 / 3656$ \\
\hline
\end{tabular}

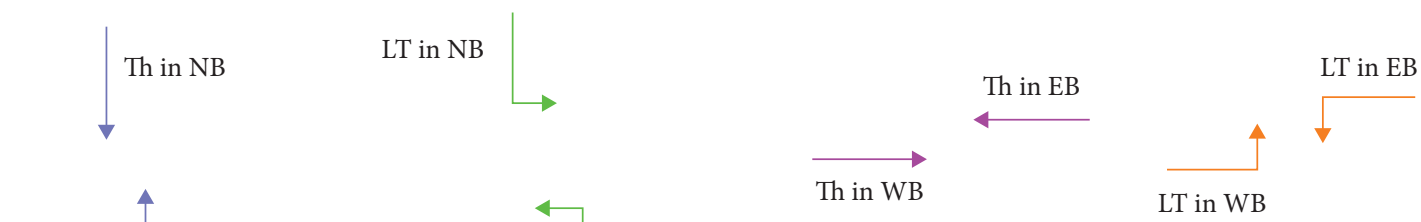

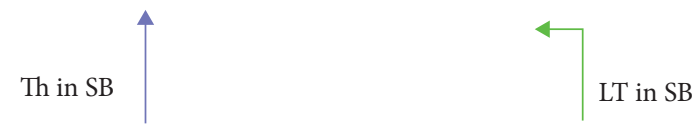

Stage 1

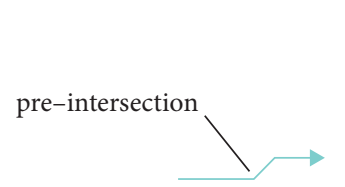

$\mathrm{LT}$ in WB

\section{$\mathrm{T}$ in SB}

Stage 2

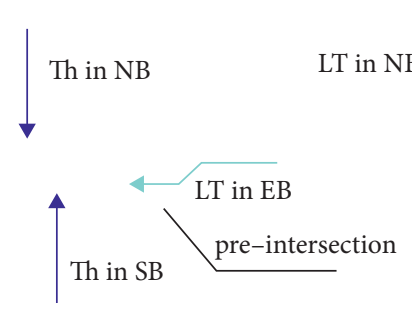

Stage 1

(a)

Stage 3

Stage 4

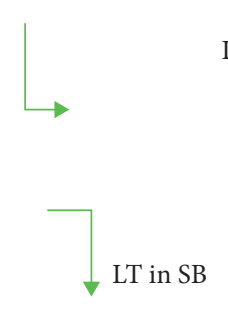

Stage 2

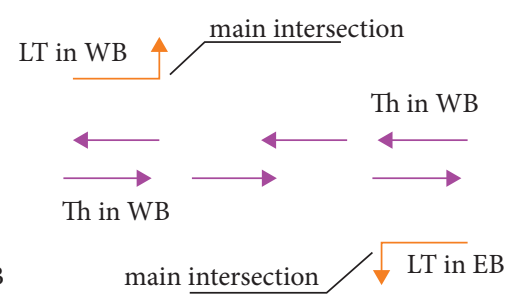

Stage 3

(b)

FIGURE 8: Signal timing stage diagram for existing intersection and improvement schemes with added DLT lanes. (a) Existing intersection. (b) Improvement intersections with added DLT lanes. EB, WB, NB, and SB denote Eastbound, Westbound, Northbound, and Southbound, respectively. LT and Th denote Left-Turn and Through, respectively.

percentages were concentrated between $10 \%$ and $35 \%$. The maximum improvement percentage was $37 \%$ when the traffic volume in the east-west direction was $2744 \mathrm{veh} / \mathrm{h}$ and $1828 \mathrm{veh} / \mathrm{h}$ in the north-south direction. In Scheme 3, there was also positive growth in each traffic volume. The average percentage of the vehicle delay improvement was up to $41 \%$ under the same traffic volume with Scheme 2. In the case of Scheme 4 , the average delay upgrade percentages were mainly in the range of $15 \%-45 \%$. And, the highest advancement percentage was $46.4 \%$ also in the case where Scheme 2 reaches its maximum improvement ratio. In Scheme 5, the advance ratios were also concentrated between $15 \%$ and $45 \%$ compared to a traditional intersection and reached a maximum of $45.8 \%$ in the same case as Scheme 2.

In other words, the comparative analysis showed that, as the added DLT lanes gradually increased from 45 to $120 \mathrm{~m}$, the improvement percentage of the average vehicle delay also increased. When the DLT lanes exceeded $120 \mathrm{~m}$ and increased to $145 \mathrm{~m}$, there was a slight decrease.

Figure 11 shows the improvement in the number of stops for the five advanced schemes compared to the traditional situation. For all the five schemes when the input traffic volume in the east-west direction was less than $1029 \mathrm{veh} / \mathrm{h}$, a development in the average number of stops was not evident, but when the traffic volume in the east-west direction exceeded $1029 \mathrm{veh} / \mathrm{h}$ and gradually increased, the improvement effect of the scheme became gradually distinct. In the case of Scheme 1, the number of stops' upgrade ratios was concentrated between $5 \%$ and $40 \%$. When the traffic volume in the east-west direction was $2744 \mathrm{veh} / \mathrm{h}$ and $1828 \mathrm{veh} / \mathrm{h}$ in the north-south direction, the advancement percentage was up to $43.8 \%$. In Scheme 2, the range of the upgrade ratios was similar to that of Scheme 1, while the 


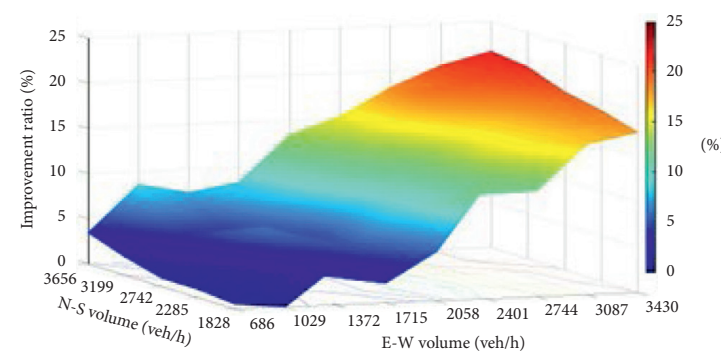

(a)

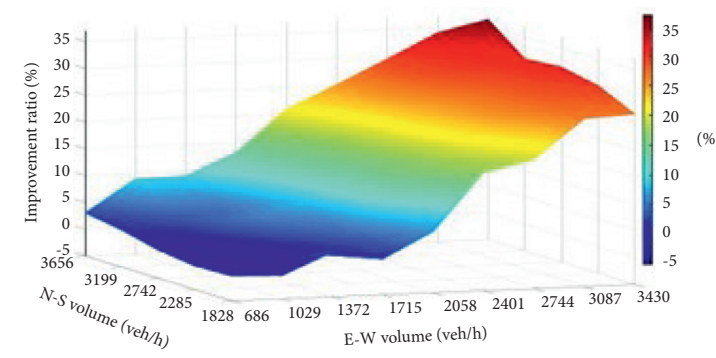

(c)

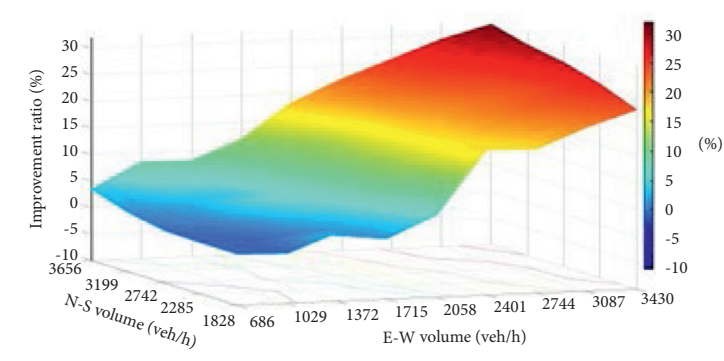

(b)

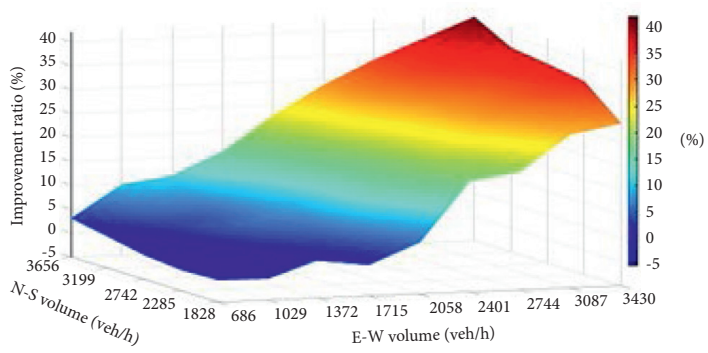

(d)

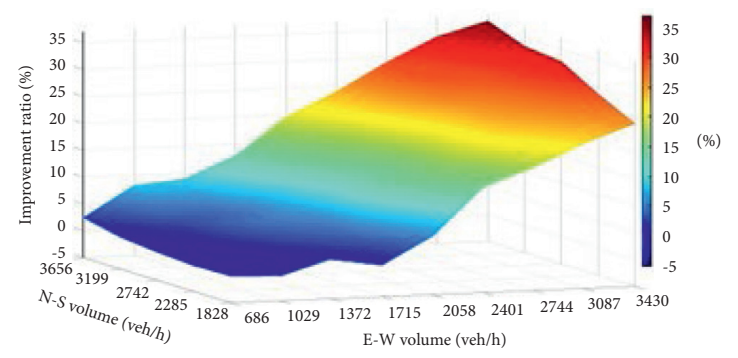

(e)

Figure 9: Improvement ratios of capacity. (a) Scheme 1. (b) Scheme 2. (c) Scheme 3. (d) Scheme 4 . (e) Scheme 5. E-W volume means the same traffic volume of east entrance and west entrance. N-S volume means the same traffic volume of north entrance and south entrance.

development percentage was up to $47.6 \%$ at the same traffic volume as Scheme 1. In the case of Scheme 3, the average number of stops' improvement percentages is mainly in the range of $5 \%-50 \%$, and the upgrade ratio was up to $53.8 \%$ at the same traffic volume as Scheme 2. In Scheme 4, the upgrade ratio reached a maximum of $60 \%$ under the same traffic volume as the three previous schemes. In Scheme 5, like the four advanced schemes mentioned above, the ratios increased with the increase in east-west traffic volume. The biggest enhancement percentage occurred in the same circumstance. And, the increasing percentage at this time was $55.7 \%$.

In short, for all five advanced schemes, regardless of the lengths of the DLT lanes, there was no significant growth in the number of stops for vehicles when the traffic volume in the east-west direction was low. On the one hand, as the traffic volume in the east-west direction gradually increased, advantages of increasing the DLT improvement program gradually emerged. On the other hand, a horizontal comparison showed that, as the lengths of the DLT lanes increased from 45 to $120 \mathrm{~m}$, the enhancement effect increased with the increase in length; however, when the lengths of the DLT lanes increased from 120 to $145 \mathrm{~m}$, and there was a small decrease in the improvement in the average number of stops.
Figure 12 shows the improvements in the NOx emissions indicators of the five progressive schemes compared to the traditional intersection. It was found that the enhancement effects of the five improved schemes were roughly the same as those of the current traditional intersections. The upgrade effects were not obvious in the 45 combinations of traffic volume, and negative changes were shown in most cases. The maximum improvement percentages of the schemes appeared when the traffic volume in the east-west direction was $2058 \mathrm{veh} / \mathrm{h}$ and $1828 \mathrm{veh} / \mathrm{h}$ in the north-south direction. The improvement percentages gradually increased from Scheme 1 to Scheme 4, i.e., $10.6 \%, 12.9 \%, 18.2 \%$, and $21 \%$. Meanwhile, the maximum percent of Scheme 5 was $17.6 \%$. Generally speaking, because the traffic capacity of the advanced scheme was higher than that of the traditional scheme, the nitrogen oxide content emitted by vehicles in the entire intersection area did not significantly improve compared to the traditional intersection scheme for the same duration. There was even a slight increase in emissions.

Corresponding to the east-west traffic flow with DLT lanes, this part focuses on comparing and analyzing the differences in the travel time of the east-west imported leftturning vehicles under different traffic volume combinations for the east-west traffic flow with DLT lanes. 


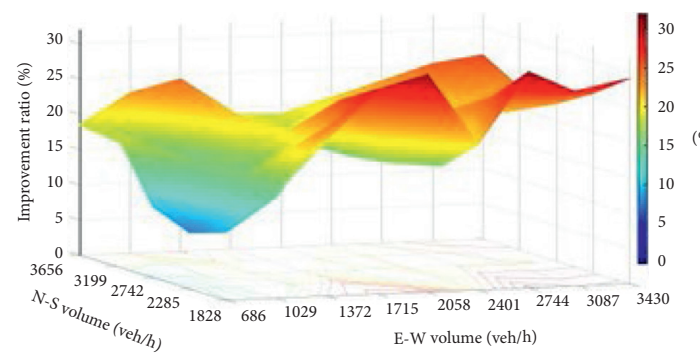

(a)

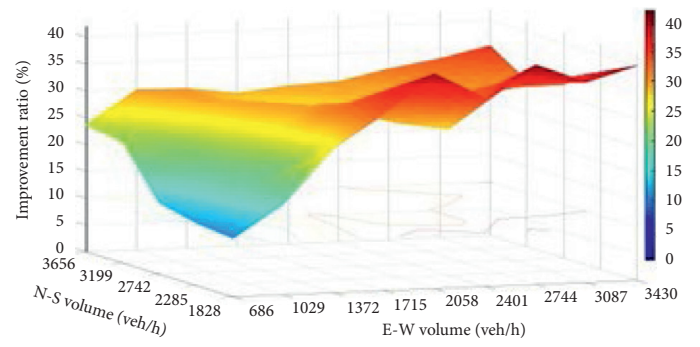

(c)

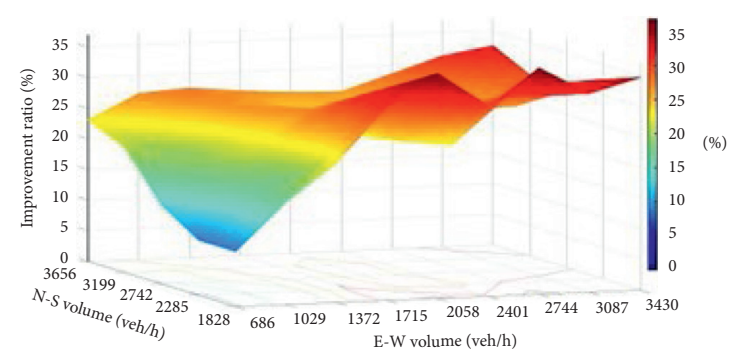

(b)

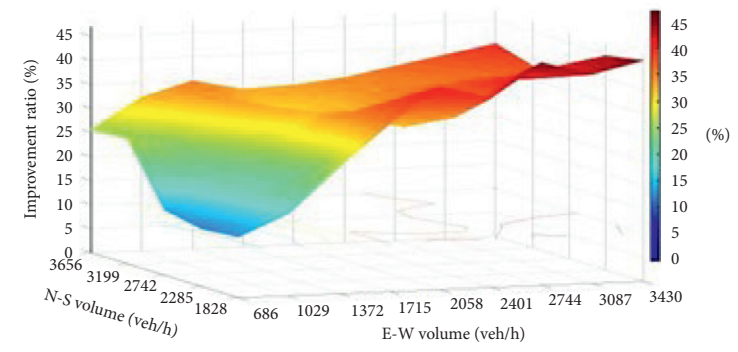

(d)

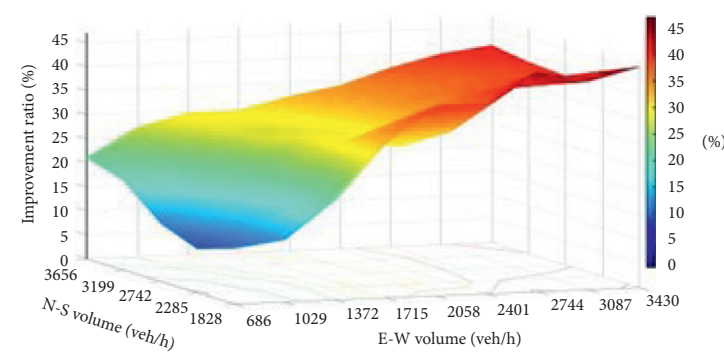

(e)

Figure 10: Improvement ratios of delays. (a) Scheme 1. (b) Scheme 2. (c) Scheme 3. (d) Scheme 4. (e) Scheme 5. E-W volume means the same traffic volume of east entrance and west entrance. N-S volume means the same traffic volume of north entrance and south entrance.

Figure 13 shows the travel time of left-turning vehicles at the west entrance. The travel time was recorded from the point where the vehicle reached $100 \mathrm{~m}$ before the main intersection to the point where the vehicle drove $100 \mathrm{~m}$ away from the main intersection. In Scheme 1, the simulation experiment results showed negative changes under all 45 traffic volume combinations. This is because the DLT lane has subintersections and left-turning vehicles pass through the entire level intersection, meaning that vehicles need to pass through two signal-controlled intersections. On the contrary, it also showed that the length of the $45 \mathrm{~m}$ DLT lane was set too short to reduce the travel time of left-turning vehicles. In Scheme 2, the travel time of left-turning vehicles at the west entrance could be obviously improved under most traffic conditions, with the highest advancement percentage reaching 30\%. In Scheme 3, the improvement effect of the driving time of left-turning vehicles at the west entrance was more distinct than that in the second scheme. The enhancement percentage under most traffic conditions was more than $30 \%$, and the largest advancement percentage reached $62.5 \%$. In Scheme 4 , the enhancement percentage of the driving time of left-turning vehicles at the west entrance also exceeded $30 \%$ in most cases, and the maximum improvement percentage reached $65.8 \%$. When the lengths of the DLT lanes increased to $145 \mathrm{~m}$, the maximum enhancement percentage of the driving time of left-turning vehicles at the west entrance was $55.8 \%$.

Figure 14 shows the improvement in the driving time of left-turning vehicles at the east entrance. In Scheme 1, the driving time of left-turning vehicles at the east entrance was similar to the situation at the west entrance, and Scheme 1 showed a negative change compared to the traditional scheme. Additionally, the largest negative upgrade ratio even reached $-90 \%$. In Scheme 2, the driving time of leftturning vehicles showed a positive development in most cases, and the percentage of enhancement was concentrated in the range of $10 \% \sim 20 \%$. In the case of Scheme 3, the advancement effect of the driving time of left-turning vehicles was more obvious. Under various traffic volume combinations, the driving time of left-turning vehicles improved, and the growth percentage was concentrated in the $30 \% \sim 50 \%$ range. In the case of Scheme 4 , the driving time of left-turning vehicles also improved under all circumstances, and the increasing percentage was concentrated in the $40 \% \sim 60 \%$ range. When using Scheme 5 , the development under the 45 traffic volume combinations was positive, and the advancement percentage was mostly between $40 \%$ and $70 \%$. 


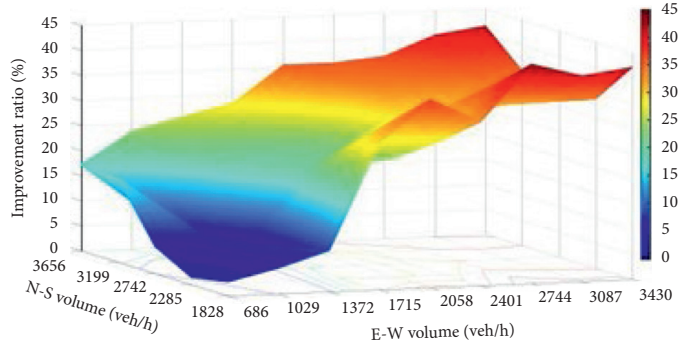

(a)

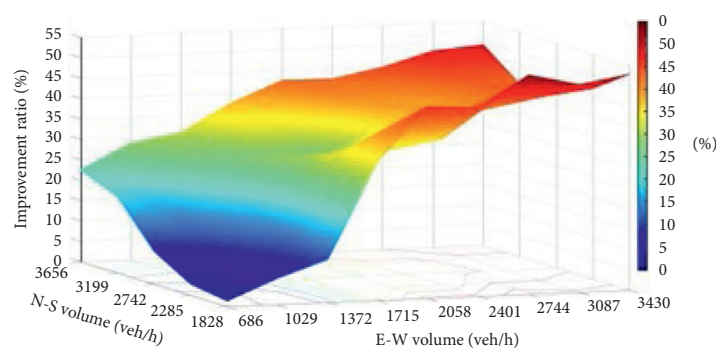

(c)

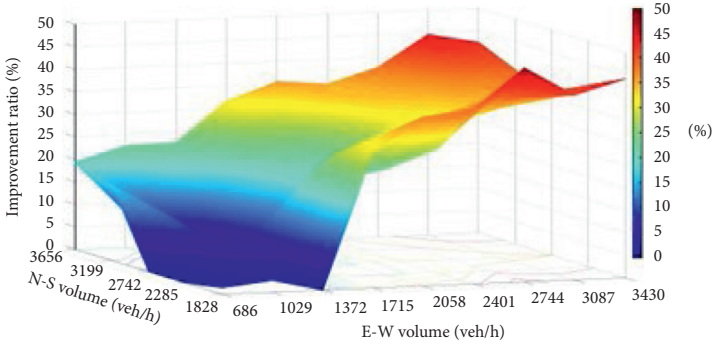

(b)

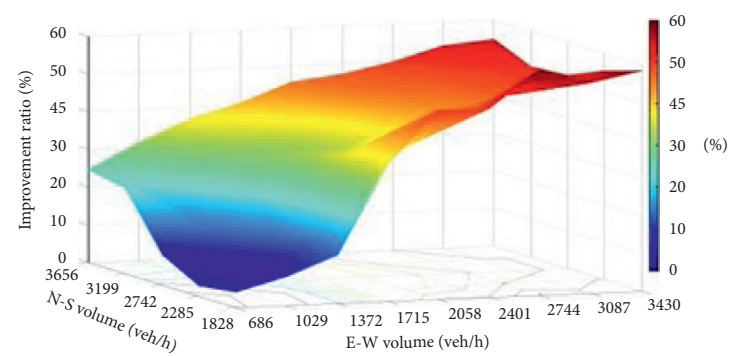

(d)

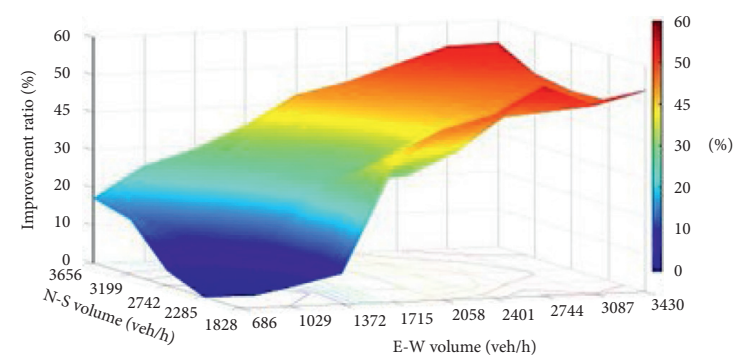

(e)

Figure 11: Improvement ratios of the number of stops. (a) Scheme 1. (b) Scheme 2. (c) Scheme 3. (d) Scheme 4. (e) Scheme 5. E-W volume means the same traffic volume of east entrance and west entrance. N-S volume means the same traffic volume of north entrance and south entrance.

4.2. Weight of Four Indexes Based on Entropy Method. As mentioned above, four commonly used indicators were selected for the scheme comparison and selection of this part:

$$
\begin{aligned}
C & =C_{45 \times 6}, \\
D & =D_{45 \times 6}, \\
S & =S_{45 \times 6}, \\
N & =N_{45 \times 6},
\end{aligned}
$$

where $C$ denotes the matrix of capacity, $D$ denotes the matrix of average vehicle delays, $S$ denotes the matrix of the number of stops, and $N$ denotes the matrix of NOx emissions.

The above four indexes' simulation results of the six schemes with 45 different traffic combinations were calculated step by step according to equations (2)-(15). The weights of the four indexes are shown in following Table 8:

4.3. Scheme Comparison. According to equation (6), processing the simulation results generates the matrix $J$. And, in this case study, the first row $J_{1}$ of the matrix $J$ could be obtained as follows:

$$
J_{1}=[2,5,5,1] .
$$

Then, the first row $X_{1}$ of the matrix $X$ can be obtained from equations (17) and (18) as follows:

$$
X_{1}=[0.3341,0.1595,0,0,0.5064,0] .
$$

The first column represents the score of Scheme 0 , the second column represents the score of Scheme 1, and so on; the last column represents the score of Scheme 5. And, the results in the first row show the recommended length of the DLT lanes for Scheme 4 under the first traffic volume combination.

The first element of the matrix $R$ is

$$
r_{1}=4 \text {. }
$$

Finally, the matrix $R$ contains 45 scheme numbers that represent the best scheme for each combination of traffic volumes. Matrix $R$ was transposed into a new $9 \times 5$ matrix $R$, and the final result is shown in Figure 15:

Figure 15 shows a comparison of the six scenarios for all 45 traffic volume combinations, and the color block in the figure shows a clear regularity. In the lower-left corner, 


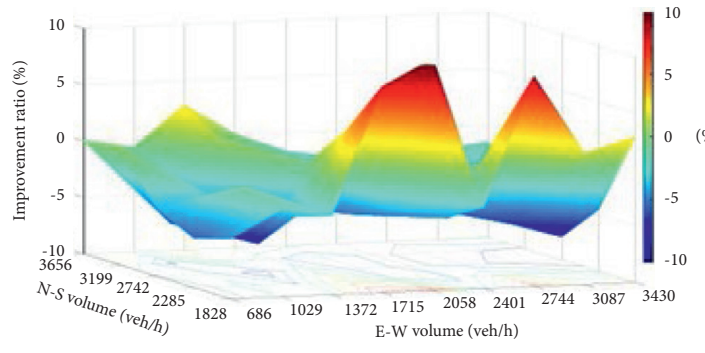

(a)

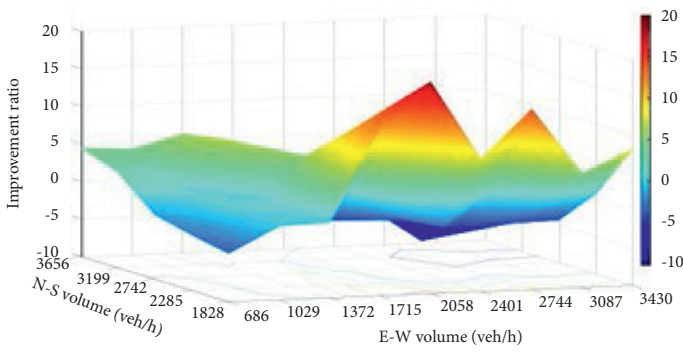

(c)

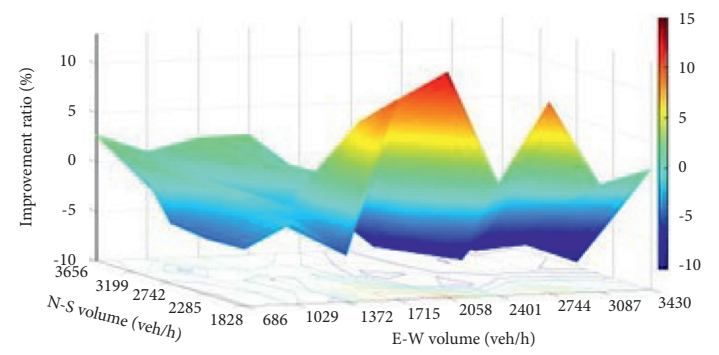

(b)

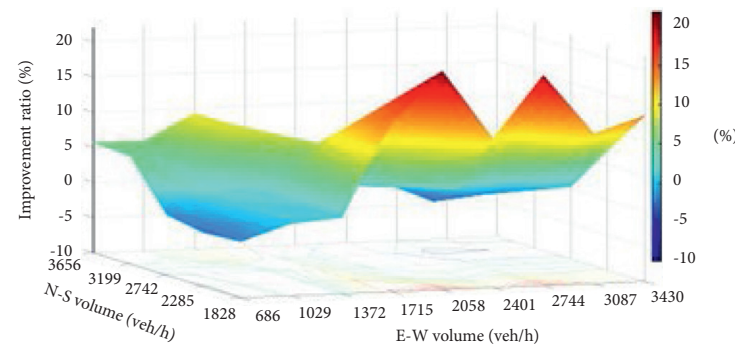

(d)

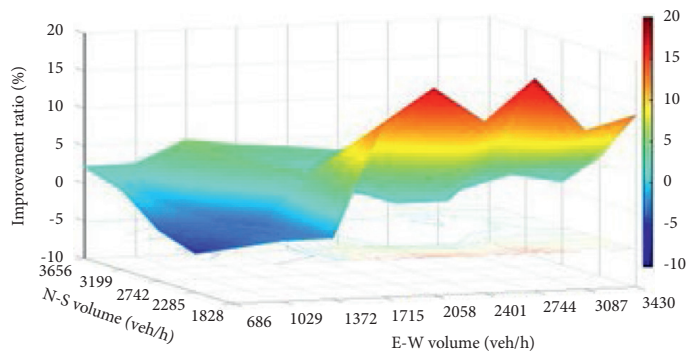

(e)

Figure 12: Improvement ratios of the NOx emissions. (a) Scheme 1. (b) Scheme 2. (c) Scheme 3. (d) Scheme 4. (e) Scheme 5. E-W volume means the same traffic volume of east entrance and west entrance. N-S volume means the same traffic volume of north entrance and south entrance.

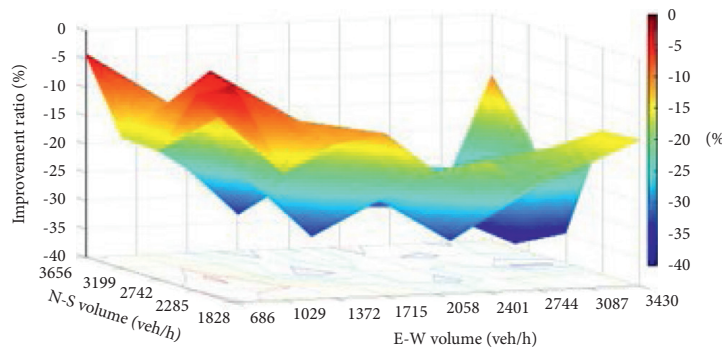

(a)

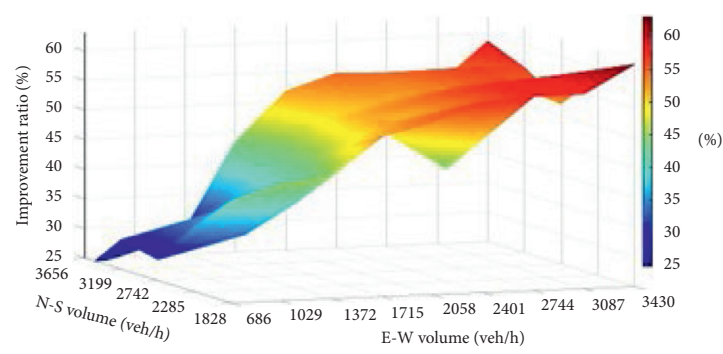

(c)

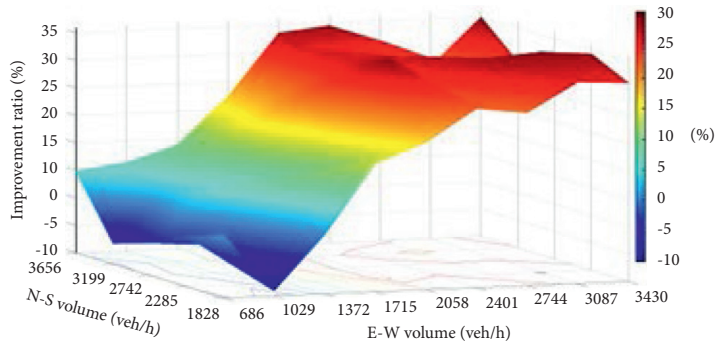

(b)

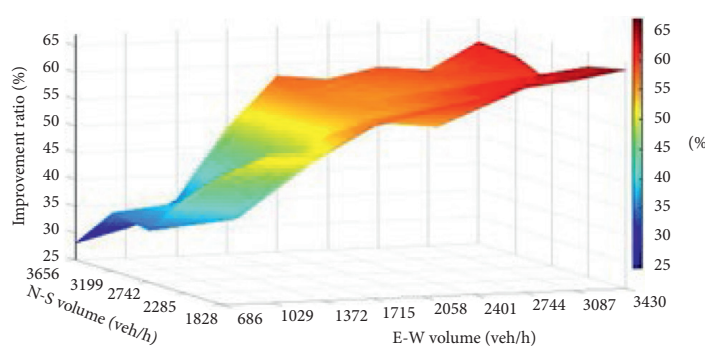

(d)

Figure 13: Continued. 


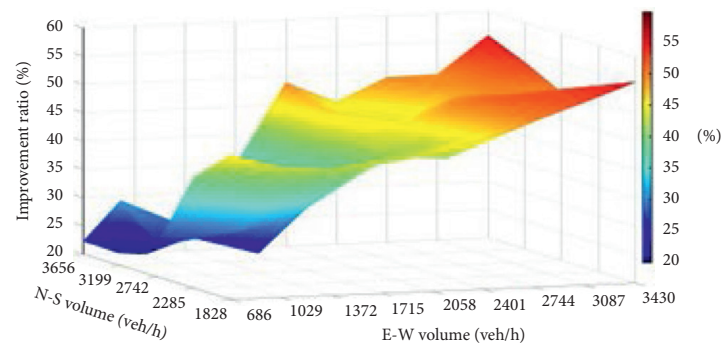

(e)

Figure 13: Improvement ratios of the left-turning time at the west entrance. (a) Scheme 1. (b) Scheme 2. (c) Scheme 3. (d) Scheme 4. (e) Scheme 5. E-W volume means the same traffic volume of east entrance and west entrance. N-S volume means the same traffic volume of north entrance and south entrance.

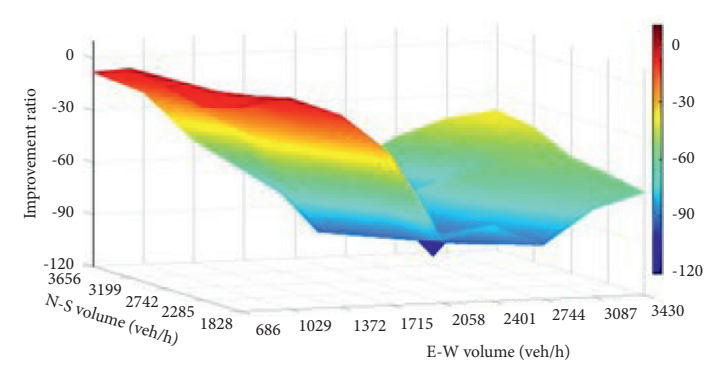

(a)

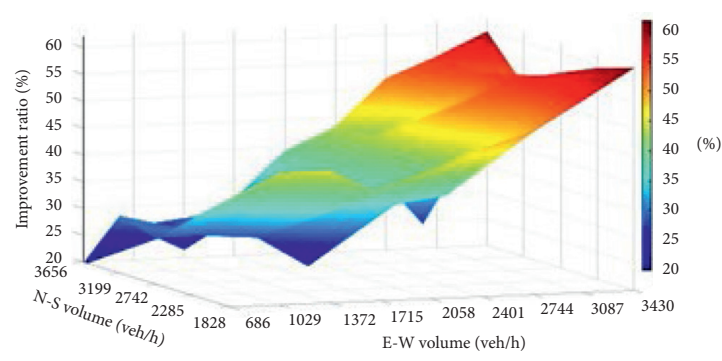

(c)

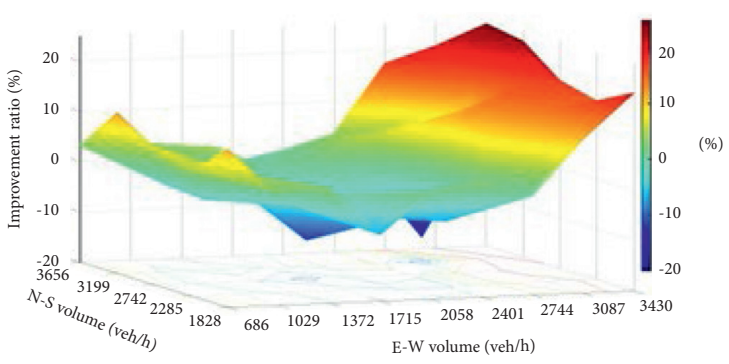

(b)

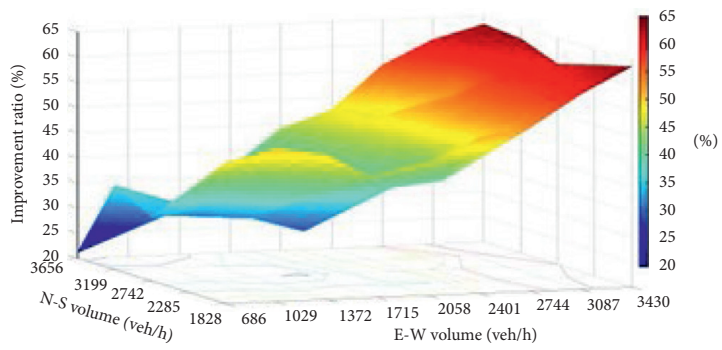

(d)

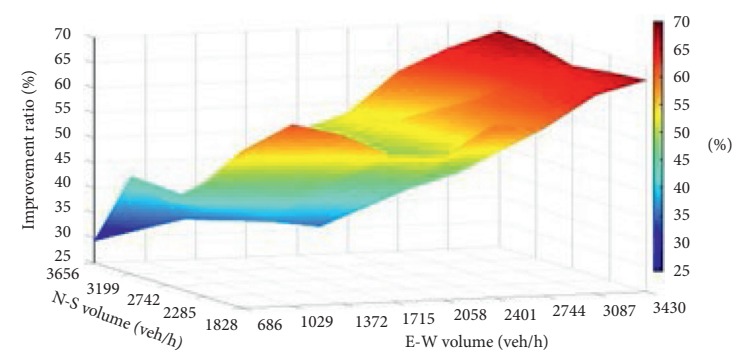

(e)

Figure 14: Improvement ratios of the left-turning time at the east entrance. (a) Scheme 1. (b) Scheme 2. (c) Scheme 3. (d) Scheme 4. (e) Scheme 5. E-W volume means the same traffic volume of east entrance and west entrance. N-S volume means the same traffic volume of north entrance and south entrance.

TABLE 8: Weights of the four indexes.

\begin{tabular}{lccccc}
\hline Index & $C$ & $D$ & $S$ & $N$ & Sum \\
\hline Weight & 0.1595 & 0.2905 & 0.2159 & 0.3341 & 1 \\
\hline
\end{tabular}




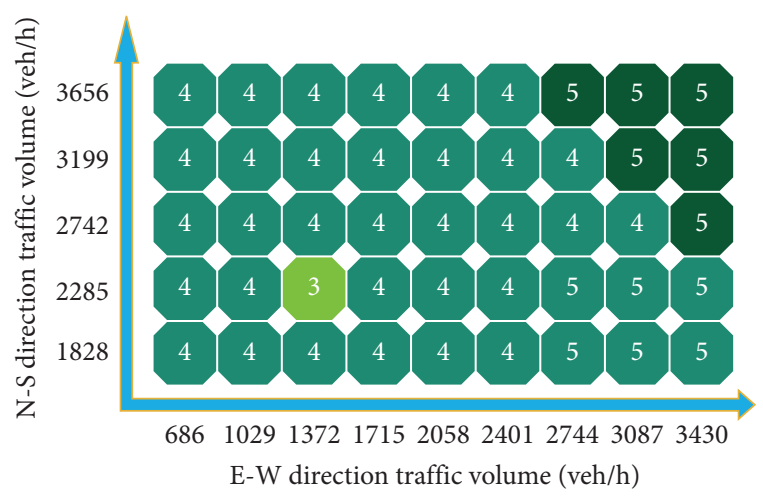

Figure 15: Recommended schemes' matrix diagram. The figure shows the recommended schemes in the different traffic combinations.

either Scheme 4 or Scheme 3 performed well when the traffic volume in both the east-west and north-south directions was small. However, when the traffic volume in both the eastwest and north-south directions was getting larger, Scheme 5 showed its advantages in improving pollutant emission and became the recommended scheme. In general, Scheme 4 was the recommended solution for most cases because of its superior overall performance. In the final results of the recommended scheme, Scheme $3 /$ Scheme $4 /$ Scheme $5=1$ : $38: 6$. The recommended length obtained using the evaluation and analysis model met the recommended range of 300-500 feet in the guidebook on DLT intersections published by Federal Highway Administration [48], indicating that the results obtained from the model are scientific and reasonable.

\section{Conclusions}

The expanding urbanization exacerbates the problem of urban road congestion in China. Upgrading urban road intersections is one of the keys to solving this problem. The DLT intersection has been widely recognized as an unconventional intersection, which can improve traffic efficiency when the left-turn traffic flow is heavy. However, the current design of this unconventional intersection mainly relies on empirical methods and mathematical methods, and there are many deficiencies needed to be further overcome.

This paper investigated a model for determining the recommended length of added DLT lanes by using the VISSIM traffic simulation model and SSAM security evaluation model. Both VISSIM and SSAM were calibrated to ensure reliability, which could provide meaningful support for designing more efficient and safer DLT intersections. Considering the multiobjective decision on intersection design, the EEM was utilized in the model not only to solve the problem of multiparameter processing but also to ensure objectivity and avoid the controversy of artificial interference. The research carried out in this paper took a traditional cross intersection located in Xi'an, Shaanxi Province, China, as a case study. Only the west entrance had obvious transition and widening sections. The specific situation was shown in Figure 3. There was a large amount of left-turning traffic flows in the east-west direction of the present intersection. Then, we designed development schemes with different lengths of added DLT lanes to deal with this problem. They performed better in efficiency and safety. The results showed that the development intersections with added DLT lanes significantly reduced the number of conflicts compared with the existing intersection, especially in the "rear end" and "lane change." Another important finding was that the change in the number of conflicts was not obvious as the length of the DLT lanes changed. Afterward, we conducted a sensitivity analysis of the improved schemes and the existing scheme under 45 different traffic combinations.

Using the model, the length of the $120 \mathrm{~m}$ long added DLT lanes at the crossing intersection which was recommended under most of the traffic volume combinations in this case. This was probably because setting $120 \mathrm{~m}$ added DLT lanes provided the superb balance of increasing capacity, reducing delays, and environmental protection.

And, the recommended length should not be less than $95 \mathrm{~m}$ under all of the 45 traffic conditions. This was probably because the additional DLT lanes were too short to meet the demand of vehicles that need to turn left, and the new schemes added subintersection, which might have negative changes compared to the traditional intersections.

The research proves that the added DLT lane length evaluation and analysis model proposed in this paper can eliminate the controversy of subjective human factors and achieve multiobjective optimization projects. It also proves that the evaluation and analysis model is advanced, reasonable, and maneuverable, and the considering multifactor design process for determining the recommended length of added DLT lanes with applying the analysis model also has good practicability. It can provide meaningful guidance for the designers in the design of the reconstructed DLT intersections.

Some issues in this paper that need to be further enriched and improved.

(i) Budget constraints can be added to the model to select the recommended scheme

(ii) In the future, the model also needs to consider how to compare schemes of different lane lengths when the number of DLT lanes' changes

\section{Data Availability}

The data used to support the findings of this study are available from the corresponding author upon request.

\section{Conflicts of Interest}

The authors declare that there are no conflicts of interest regarding the publication of this paper.

\section{Acknowledgments}

This study was supported by Scientific Research Program funded by Shaanxi Provincial Education Department (Program no. 21JK0908). 


\section{References}

[1] Baidu Map, 2020 China Urban Transport Report, Baidu Map Publications, Shenzhen, China, 2021.

[2] J. Lioris, R. Pedarsani, F. Y. Tascikaraoglu, and P. Varaiya, "Platoons of connected vehicles can double throughput in urban roads," Transportation Research Part C: Emerging Technologies, vol. 77, pp. 292-305, 2017.

[3] Y. Xiang, Z. Li, W. Wang, J Chen, H Wang, and Y Li, "Evaluating the operational features of an unconventional dual-bay U-turn design for intersections," PLoS One, vol. 11, no. 7, Article ID e0158914, 2016.

[4] Y. Shao, X. Han, H. Wu, H Shan, S Yang, and C. G Claudel, "Evaluating the sustainable traffic flow operational features of an exclusive spur dike U-turn lane design," PLoS One, vol. 14, no. 4, Article ID e0214759, 2019.

[5] H. Naghawi and W. Idewu, "Analysing delay and queue length using microscopic simulation for the unconventional intersection design Superstreet," Journal of the South African Institution of Civil Engineers, vol. 56, pp. 100-107, 2005.

[6] J. G. Bared, P. K. Edara, and R. Jagannathan, "Design and operational performance of double crossover intersection and diverging diamond interchange," Transportation Research Record: Journal of the Transportation Research Board, vol. 1912, no. 1, pp. 31-38, 2005.

[7] A. Dhatrak, P. Edara, and J. G. Bared, "Performance analysis of parallel flow intersection and displaced left-turn intersection designs," Transportation Research Record: Journal of the Transportation Research Board, vol. 2171, no. 1, pp. 33-43, 2010.

[8] J. Bared, W. Hughes, R. Jagannathan, and J. E. Hummer, Alternative Intersections/interchanges: Informational Report (AIIR) (No. FHWA-HRT-09-060), Federal Highway Administration, Office of Research, McLean, VA, USA, 2010.

[9] J. Wu, A. Abbas-Turki, A. Correia, and A. E. Moudni, "Discrete intersection signal control," in Proceedings of the IEEE International Conference on Service Operations and Logistics, and Informatics, Philadelphia, PA, USA, August 2007.

[10] L. Zhang, Q. Zhao, L. Wang, and L. Zhang, "Research on urban traffic signal control systems based on cyber physical systems," Journal of Advanced Transportation, vol. 2020, Article ID 8894812, 16 pages, 2020.

[11] C. Yu, Y. Feng, H. X. Liu, W. Ma, and X. Yang, "Integrated optimization of traffic signals and vehicle trajectories at isolated urban intersections," Transportation Research Part B: Methodological, vol. 112, pp. 89-112, 2018.

[12] C. Yu, W. Ma, K. Han, and X. Yang, "Optimization of vehicle and pedestrian signals at isolated intersections," Transportation Research Part B: Methodological, vol. 98, pp. 135153, 2017.

[13] Y. Li and Q. Liu, "Intersection management for autonomous vehicles with vehicle-to-infrastructure communication," PLoS One, vol. 15, no. 7, Article ID e0235644, 2020.

[14] J. Olsson and M. W. Levin, "Integration of microsimulation and optimized autonomous intersection management," Journal of Transportation Engineering Part A-System, vol. 146, no. 9, 2020.

[15] S. Ilgin Guler, M. Menendez, and L. Meier, "Using connected vehicle technology to improve the efficiency of intersections," Transportation Research Part C: Emerging Technologies, vol. 46, pp. 121-131, 2014.

[16] J. Appiah, F. A. King, M. D. Fontaine, and B. H. Cottrell, "Left turn crash risk analysis: development of a microsimulation modeling approach," Accident Analysis \& Prevention, vol. 144, Article ID 105591, 2020.

[17] H. Chen, N. Zhang, and Z. Qian, "VISSIM-based simulation of the left-turn waiting zone at signalized intersection," International Conference on Intelligent Computation Technology and Automation, vol. 1, pp. 736-740, 2008.

[18] Z. Yang, P. Liu, Z. Z. Tian, and W. Wang, "Evaluating the operational impact of left-turn waiting areas at signalized intersections in China," Transportation Research Record, vol. 2286, no. 1, pp. 12-20, 2008.

[19] Q. Bai, Z. Gao, Z. Qu, and C. Tao, "Modeling for left-lane line extensions at signalized intersections with permitted leftturning phase," Journal of Transportation Engineering Part A-Systems, vol. 146, no. 8, 2020.

[20] Y. Zheng, X. Hua, W. Wang, J. Xiao, and D. Li, “Analysis of a signalized intersection with dynamic use of the left-turn lane for opposite through traffic," Sustainability, vol. 12, no. 18, 2020.

[21] M. M. A. Al-Omari, M. Abdel-Aty, J. Lee, L. Yue, and A. Abdelrahman, "Safety evaluation of median U-turn crossover-based intersections," Transportation Research Record: Journal of the Transportation Research Board, vol. 2674, no. 7, pp. 206-218, 2020.

[22] Y. Xuan, C. F. Daganzo, and M. J. Cassidy, "Increasing the capacity of signalized intersections with separate left turn phases," Transportation Research Part B: Methodological, vol. 45, no. 5, pp. 769-781, 2011.

[23] R. Jagannathan and J. G. Bared, "Design and operational performance of crossover displaced left-turn intersections," Geometric design and the effects on traffic operations, vol. 1881, no. 1, pp. 1-10, 2004.

[24] W. Qu, Q. Sun, Q. Zhao, T. Tao, and Y. Qi, "Statistical analysis of safety performance of displaced left-turn intersections: case studies in San Marcos, Texas," International Journal of Environmental Research and Public Health, vol. 17, no. 18, 2020.

[25] A. Abdelrahman, M. Abdel-Aty, J. Lee, L. Yue, and M. M. A. Al-Omari, "Evaluation of displaced left-turn intersections," Transport Engineer, vol. 1, no. 100006, 2020.

[26] W. Suh and M. P. Hunter, "Signal design for displaced leftturn intersection using Monte Carlo method," KSCE Journal of Civil Engineering, vol. 18, no. 4, pp. 1140-1149, 2014.

[27] W. Qu, S. Liu, Q. Zhao, and Y. Qi, "Development of a progression-based signal-timing strategy for continuous-flow intersections," Journal of Transportation Engineering Part A-Systems, vol. 147, no. 3, pp. 1-11, 2021.

[28] X. Hua, J. Yang, W. Wang, and H. Wang, "Operation optimization of signalized tandem intersections with displaced left turn," in Proceedings of the Transportation Research Board 97th Annual Meeting, Washington, DC, USA, January 2018.

[29] J. Zhao, W. Ma, K. L. Head, and X. Yang, "Optimal operation of displaced left-turn intersections: a lane-based approach," Transportation Research Part C: Emerging Technologies, vol. 61, pp. 29-48, 2015.

[30] J. Zhao, X. Gao, and V. L. Knoop, "An innovative design for left turn bicycles at continuous flow intersections," Transportation Business: Transport Dynamics, vol. 7, no. 1, pp. 1305-1322, 2019.

[31] W. Sun, X. Wu, Y. Wang, and G. Yu, "A continuous-flowintersection-lite design and traffic control for oversaturated bottleneck intersections," Transportation Research Part C: Emerging Technologies, vol. 56, pp. 18-33, 2015.

[32] J. D. Reid and J. E. Hummer, "Travel time comparisons between seven unconventional arterial intersection designs," in Geometric Design and the Effects on Traffic Operation 2001: 
Highway Operation, Capacity, and Traffic Control, pp. 56-66, no. 1751, Transportation Research Record, Washington, DC, USA, 2001.

[33] S. Shokry, S. Tanaka, F. Nakamura, R. Ariyoshi, and S. Miura, "Bandwidth maximization approach for displaced left-turn crossovers coordination under heterogeneous traffic conditions," Journal of Traffic and Transportation Engineering, vol. 6, pp. 183-196, 2018.

[34] I. Ahmed, S. Warchol, C. Cunningham, and N. Rouphail, "Mobility assessment of pedestrian and bicycle treatments at complex continuous flow intersections," Journal of Transportation Engineering Part A-Systems, vol. 147, no. 5, pp. 1-10, 2021.

[35] E. Hassannayebi, A. Sajedinejad, and S. Mardani, "Urban rail transit planning using a two-stage simulation-based optimization approach," Simulation Modelling Practice and Theory, vol. 49, pp. 151-166, 2014.

[36] E. Hassannayebi, M. Boroun, S. A. Jordehi, and H. Kor, “Train schedule optimization in a high-speed railway system using a hybrid simulation and meta-model approach," Computers \& Industrial Engineering, vol. 138, 2019.

[37] H. Li, Z. Huang, X. Zou, S. Zheng, and Y. Yang, "VISSIMbased simulation and analysis of upstream segments in ramp areas for optimizing vehicle group lane-changing behaviors," Journal of Advanced Transportation, vol. 2020, Article ID 5983161, 11 pages, 2020.

[38] M. M. Morando, T. Q. Tian, L. T. Truong, and H. Vu, "Studying the safety impact of autonomous vehicles using simulation-based surrogate safety measures," Journal of Advanced Transportation, vol. 2018, Article ID 6135183, 11 pages, 2018.

[39] G. Tesoriere, T. Campisi, A. Canale, and T. Zgrablić, "The surrogate safety appraisal of the unconventional elliptical and turbo roundabouts," Journal of Advanced Transportation, vol. 2018, Article ID 2952074, 9 pages, 2018.

[40] G. Zhao and D. Wang, "Comprehensive evaluation of AC/DC hybrid microgrid planning based on analytic hierarchy process and entropy weight method," Applied Sciences-base, vol. 9, no. 18, 2019.

[41] T. Xie, M. Wang, C. Su, and W. Chen, "Evaluation of the natural attenuation capacity of urban residential soils with ecosystem-service performance index (EPX) and entropyweight methods," Environmental Pollution, vol. 238, pp. 222-229, 2018.

[42] Y. Cui, P. Feng, J. Jin, and L. Liu, "Water resources carrying capacity evaluation and diagnosis based on set pair analysis and improved the entropy weight method," Entropy, vol. 20, no. 5, pp. 359-379, 2018.

[43] D. Koltovska, K. Bombol, and D. Ilievski, "Calibration and validation procedure of microscopic traffic simulation model: a case study," in Proceedings of the Second International Conference on Traffic and Transport Engineering (ICTTE), pp. 80-87, Belgrado, Sérvia, April 2014.

[44] Z. Li, M. V. Chitturi, D. Zheng, A. R. Bill, and D. A. Noyce, "Modeling reservation-based autonomous intersection control in VISSIM," Computers \& Industrial Engineering, vol. 2381, no. 1, pp. 81-90, 2013.

[45] Federal Highway Administration Research and Technology, Surrogate Safety Assessment Model (SSAM), Federal Highway Administration, Washington, DC, USA, 2020.

[46] Federal Highway Administration (FHWA), Techbrief Surrogate Safety Assessment Model (SSAM), Federal Highway Administration, Washington, DC, USA, 2008.
[47] Transportation Researcher Board (TRB), Highway Capacity Manual, Transportation Researcher Board, Washington DC, USA, 6th edition, 2016.

[48] Federal Highway Administration (FHWA), Displaced LeftTurn Intersection Informational Guide, Federal Highway Administration, Washington DC, USA, 2014. 